Working Paper/Document de travail 2012-13

\title{
Changes in the Effects of Monetary Policy on Disaggregate Price Dynamics
}

by Christiane Baumeister, Philip Liu and Haroon Mumtaz 
Bank of Canada Working Paper 2012-13

April 2012

\title{
Changes in the Effects of Monetary Policy on Disaggregate Price Dynamics
}

by

\author{
Christiane Baumeister, ${ }^{1}$ Philip Liu ${ }^{2}$ and Haroon Mumtaz ${ }^{3}$ \\ 1International Economic Analysis Department \\ Bank of Canada \\ Ottawa, Ontario, Canada K1A 0G9 \\ cbaumeister@bankofcanada.ca \\ 2International Monetary Fund \\ pliu@imf.org \\ ${ }^{3}$ Bank of England \\ haroon.mumtaz@bankofengland.co.uk
}

Bank of Canada working papers are theoretical or empirical works-in-progress on subjects in economics and finance. The views expressed in this paper are those of the authors.

No responsibility for them should be attributed to the Bank of Canada, the Bank of England or the International Monetary Fund. 


\section{Acknowledgements}

We have benefitted from discussions with Ron Alquist, Luca Benati, Sylvia Kaufmann, Lutz Kilian, Thomas Laubach, Gert Peersman, Simon Price, Paolo Surico, Bob Tetlow, Rob Vigfusson, and participants at the Banca d'Italia $2^{\text {nd }}$ International Conference in Memory of Carlo Giannini, the $15^{\text {th }}$ International Conference on Computing in Economics and Finance and the Bundesbank seminar. We are grateful to Carlos Carvalho and Jouchi Nakajima for sharing their code for multi-sector models with us. 


\begin{abstract}
We examine the evolution of the effects of monetary policy shocks on the distribution of disaggregate prices and quantities of personal consumption expenditures to assess the contribution of monetary policy to changes in U.S. inflation dynamics. Given that the transmission of monetary policy to aggregate inflation is determined by the responses of its underlying components, the degree of monetary non-neutrality is ultimately the result of relative price effects at the sectoral level. We provide evidence of considerable heterogeneity in sectoral price responses by introducing time variation in a factoraugmented vector autoregression model. Over time the majority of individual prices respond negatively after a contractionary monetary policy shock and the price dispersion diminishes. We link these empirical findings to a multi-sector DSGE model and show that they are consistent with firms' heterogeneous pricing decisions and changes in the importance of the cost channel of monetary policy and the degree of wage flexibility.
\end{abstract}

JEL classification: E30, E32

Bank classification: Transmission of monetary policy; Econometric and statistical methods

\title{
Résumé
}

Les auteurs examinent l'évolution de l'incidence des chocs de politique monétaire sur la distribution des prix individuels et des volumes de consommation des ménages afin d'évaluer comment la politique monétaire influe sur la dynamique de l'inflation aux États-Unis. Comme la réaction de l'inflation globale aux chocs de politique monétaire est déterminée par celle de ses composantes sous-jacentes, le degré de non-neutralité monétaire résulte au bout du compte des effets de prix relatifs au niveau sectoriel. Les auteurs constatent une forte hétérogénéité des comportements de prix entre secteurs lorsqu'ils utilisent un modèle FAVAR à coefficients variables dans le temps. La majorité des prix diminuent après un choc de politique monétaire négatif et la dispersion des prix s'atténue. Les auteurs lient ces résultats empiriques à un modèle d'équilibre général dynamique et stochastique multisectoriel et montrent que ceux-ci cadrent avec l'hétérogénéité des décisions de prix des entreprises et les variations de l'importance du canal du coût marginal de production et du degré de flexibilité des salaires.

Classification JEL : E30, E32

Classification de la Banque : Transmission de la politique monétaire; Méthodes

économétriques et statistiques 


\section{Introduction}

In formulating policy decisions, central banks not only rely on information about the aggregate economy, but also carefully monitor sectoral conditions by conducting business surveys that provide important information about the price-setting process of firms (e.g. Blinder, 1991). For monetary authorities it is also crucial to know how their monetary actions affect the pricing decisions of firms in various sectors since this determines the effectiveness of monetary policy in stabilizing the economy as a whole. Altissimo et al. (2009), Bils and Klenow (2004) and Clark (2006) show that important differences in inflation dynamics arise at the aggregate and disaggregate level. Lastrapes (2006) and Balke and Wynne (2007) demonstrate that money supply shocks have long-run effects on the distribution of relative commodity prices implying an important degree of monetary nonneutrality. On the other hand, Boivin et al. (2009) make the case that discrepancies between aggregate and sectoral measures of inflation derive from the fact that the bulk of fluctuations in individual prices is due to sector-specific factors and that monetary policy shocks are of minor importance but induce sluggishness in price adjustment. In a recent contribution, De Graeve and Walentin (2011) show that if one takes special features of sectoral pricing behavior into account, the variance and persistence of disaggregate inflation are driven by both aggregate and idiosyncratic disturbances.

Another important empirical feature is that the volatility of inflation and output has declined considerably since the mid-1980s creating a more stable macroeconomic environment. In addition, the level and persistence of aggregate inflation have reached historical lows. ${ }^{1}$ However, little is known about the evolution of the underlying components of aggregate price and output measures. Over the last decades, macroeconomic developments such as increased monetary policy credibility, enhanced competition due to globalization, financial innovations, and technological advances might have contributed to alter the price-setting behavior across sectors which ultimately changes the way monetary policy is transmitted to the macroeconomy. The main contribution of this paper is to analyze changes in disaggregate price dynamics after a monetary policy shock, often hidden by aggregate measures, in order to inform policymakers about changes in the relative price effects of their monetary actions.

Since exploring the monetary transmission mechanism at the disaggregate level requires an empirical framework that lends itself to including information from a large number of macroeconomic indicators and sectoral variables representing various dimensions of the economy, we employ an extended version of the factor-augmented VAR (FAVAR) introduced in Bernanke et al. (2005). Given the possibility that disaggregate dynamics have changed over time, we extend the FAVAR model to allow for time variation in the coefficients and for stochastic volatility in the variances

\footnotetext{
${ }^{1}$ Evidence in support of these changes can be found in a number of recent papers including Kim and Nelson (1999b), McConnell and Pérez-Quirós (2000), Cogley and Sargent (2005) and Benati and Mumtaz (2007).
} 
of the shocks. Previously, changes in the monetary transmission mechanism have been studied for the aggregate economy by incorporating time variation into small-scale VAR models that typically consist of three variables - a short-term interest rate, a measure of real economic activity and inflation. ${ }^{2}$ One problem with this approach is that the amount of information incorporated in these models is relatively limited which has two potential consequences. First, missing variables could lead to biases in the reduced-form VAR coefficients and the estimates of persistence and volatility. Second, the omission of some variables could hinder the correct identification of structural shocks. One possible manifestation of these problems are impulse response functions that are at odds with economic theory. For instance, Bernanke et al. (2005) raise the issue that if the information set used by the econometrician is smaller than that employed by the monetary authority, then structural shocks and responses to them may be mis-measured because the empirical model excludes some variables that the central bank responds to. Similarly, Castelnuovo and Surico (2010) and Benati and Surico (2009) building on Lubik and Schorfheide (2004), argue that during periods of indeterminacy, the dynamics of the economy are characterized by a latent variable. Therefore, reduced-form and structural estimates of the VAR model may be biased when estimation is carried out over these periods. Thus, with our estimation framework, we are not only able to provide novel insights about the time-varying responses of disaggregate prices and consumption quantities, but also to re-examine the mixed evidence on possible changes in the responses of the main macroeconomic variables after a monetary policy shock reported in earlier studies addressing some of the shortcomings discussed above.

Our results suggest that the propagation mechanism of monetary disturbances is highly heterogeneous across components of personal consumption expenditures suggesting that monetary policy actions exert an important influence on relative prices in the U.S. economy. We show that a considerable fraction of sectoral prices increases at short horizons after a contractionary monetary policy shock, which however decreases from the early eighties onwards. On the other hand, we find no evidence of a price puzzle for any of the aggregate price measures throughout the sample period which indicates that the extra information is helpful in correctly identifying monetary policy shocks. In addition to considerable variation in the median responses of prices and quantities at the disaggregate level, we find that the cross-sectional distribution of responses has undergone substantial changes over the sample period. In particular, there has been a marked decline in the variance of the distribution of sectoral prices, while the median response has become more negative over time. The variance of the distribution of quantity responses has also declined, but the median response has become smaller in magnitude.

To better understand these empirical findings, we conduct a simulation exercise within a multisector sticky-price dynamic stochastic general equilibrium (DSGE) model to explore the interaction

\footnotetext{
${ }^{2}$ See, for instance, Cogley and Sargent (2005), Primiceri (2005), and Sims and Zha (2006).
} 
between the firms' heterogeneous pricing decisions and monetary policy shocks over time. We show that the presence of the cost channel of monetary policy, which leads to a temporary increase in marginal costs following a monetary tightening, is consistent with the price puzzle in the short run at a high level of disaggregation. Depending on their sector-specific frequency of price adjustment, firms respond to higher interest rates either by rising or lowering their prices, which generates cross-sectional heterogeneity in price responses. The attenuation of the disaggregate price puzzles over time can in part be explained by decreases in the sensitivity to the cost channel of monetary policy and increases in the degree of wage flexibility.

The rest of the paper is organized as follows. Section 2 introduces the empirical methodology adopted in this study and describes our large dataset. Section 3 discusses the time-varying dynamics of selected macroeconomic aggregates and of disaggregate prices and quantities in response to monetary policy shocks, and conducts a sensitivity analysis of the baseline model. Section 4 relates the empirical results to a multi-sector sticky-price model and explores how variations in various model parameters can account for changes in sectoral dynamics over time. Section 5 offers some concluding remarks.

\section{Empirical methodology}

\subsection{A time-varying FAVAR model with stochastic volatility}

Vector autoregressions (VARs) offer a convenient and flexible framework for capturing the monetary transmission mechanism. However, the assumptions made about the information structure are crucial when deciding whether a standard VAR can provide an accurate description of economic relationships. Measurement error in the endogenous variables included in the VAR can affect the precision of the estimated dynamic relationships. Furthermore, it is highly likely that the researcher only observes (and includes in the VAR model) a subset of the variables examined by the monetary authority when making its policy decisions. This omitted-variable problem can lead to a substantial bias in the VAR estimates of the impact of a shock to monetary policy (see Benati and Surico, 2009). Measurement error and omitted variables can potentially affect small-scale VAR analyses of changes in the transmission of structural shocks quite acutely. When examining time variation in impulse responses, the assumptions about the measurement of variables and the information set used by agents apply at each point in time and are more likely to be violated. If important information is excluded from the VAR, this can affect inference on the temporal evolution of impulse responses and lead to misleading conclusions about changes in the transmission mechanism.

The obvious solution to this problem is to include more variables in the VAR. However, the 
degrees of freedom constraint becomes binding quite quickly in standard datasets. ${ }^{3}$ An alternative approach is to incorporate extra information into the VAR model in the form of factors from a large cross section of economic indicators, which are included as endogenous variables in the VAR (e.g. Bernanke et al., 2005). More formally, the Bernanke et al. approach is based on the following factor model

$$
\begin{aligned}
X_{i, t} & =\bar{\Lambda}_{i} F_{t}+e_{i, t} \\
F_{t} & =\phi_{1} F_{t-1}+\phi_{2} F_{t-2}+\cdots+\phi_{P} F_{t-l}+v_{t} \\
v_{t} & =A_{0} u_{t}
\end{aligned}
$$

where $X_{i, t}$ is a panel of variables that contains a large amount of information about the current state of the U.S. economy and $F_{t}=\left\{F_{t}^{1}, \ldots, F_{t}^{K}, R_{t}\right\}$ denotes a matrix that includes $K$ latent factors that summarize the comovement among the underlying series at each date, while $e_{i, t}$ are the i.i.d. idiosyncratic components with $E\left(e_{i, t}^{\prime} e_{i, t}\right)=\Sigma^{R}$, where $\Sigma^{R}$ is a diagonal matrix. $F_{t}$ is related to $X_{i, t}$ through the factor loadings $\bar{\Lambda}_{i}$. Note that $F_{t}$ includes the federal funds rate $R_{t}$ which is assumed to be an 'observed' factor, i.e. the only variable observed by both the econometrician and the monetary authority. The economy is assumed to be driven by the set of structural shocks $u_{t}$, which are related to the reduced-form shocks via a structural matrix $A_{0}$. Given the impact matrix $A_{0}$, one can estimate the impulse response of $F_{t}$ and all the underlying variables in the panel $X_{i, t}$ through the first equation.

This model can be used to incorporate a large amount of information about the U.S. economy in the interest rate equation (via lagged factors $F_{t}^{1}, \ldots, F_{t}^{K}$ ) and is therefore less likely to suffer from omitted-variable bias and model mis-specification. Bernanke et al. (2005) show that the traditional price puzzle associated with VARs disappears in this 'Factor-Augmented' VAR (FAVAR) model.

As our interest centers on changes in the behavior of impulse responses across time, we extend the FAVAR model along two dimensions: First, we allow the dynamics of the system to be time-varying to capture changes in the propagation of structural shocks as a result of shifts in private sector behavior and/or monetary policy preferences. Second, our specification incorporates heteroscedastic shocks which account for variations in the volatility of the underlying series. This extended FAVAR model provides a flexible framework to examine changes in the transmission of structural shocks. Moreover, the time-varying FAVAR model is less likely to suffer from problems created by omitted variables and therefore provides a robust framework to examine changes in the transmission mechanism.

A number of recent papers also employ dynamic factor models with either time-varying factor

\footnotetext{
${ }^{3}$ This problem is even more acute in time-varying VARs as they usually impose a stability constraint (at each point in time) and this is less likely to be satisfied as the number of variables in the VAR increases.
} 
loadings or time-varying factor dynamics. Del Negro and Otrok (2008) were the first to incorporate time-varying factor loadings and stochastic volatility into a dynamic factor model. They use the model to study the evolution in international business cycles and report a decline in the volatility across a panel of 19 countries. Mumtaz and Surico (forthcoming) use a dynamic factor model with time variation in the dynamics of the factors to study the evolution of the common component of inflation in the industrialized world. ${ }^{4}$ The time-varying FAVAR model (and the estimation methodology) proposed in this study is closely related to models used in Del Negro and Otrok (2008) and Mumtaz and Surico (forthcoming). However, the model in this paper is designed for structural analysis, i.e. to investigate possible changes in the transmission of structural shocks. In contrast, most previous papers have used time-varying factor models for reduced-form analysis. ${ }^{5}$

The time-varying FAVAR model can be re-written in state-space format. Consider first the observation equation:

$$
\left(\begin{array}{c}
X_{1, t} \\
\ldots \\
\ldots \\
X_{N, t} \\
R_{t}
\end{array}\right)=\left(\begin{array}{ccccc}
\Lambda^{11} & \Lambda^{12} & \ldots & \Lambda^{1 K} & \Psi^{11} \\
\ldots & \ldots & \ldots & \ldots & \ldots \\
\ldots & \ldots & \ldots & \ldots & \ldots \\
\ldots & \ldots & \ldots & \Lambda^{N K} & \Psi^{N 1} \\
0 & 0 & \ldots & 0 & 1
\end{array}\right)\left(\begin{array}{c}
F_{t}^{1} \\
F_{t}^{2} \\
\ldots \\
F_{t}^{K} \\
R_{t}
\end{array}\right)+\left(\begin{array}{c}
e_{1, t} \\
\ldots \\
e_{N, t} \\
0
\end{array}\right)
$$

where $\Lambda$ 's and $\Psi$ 's are the elements of the factor loading matrix $\bar{\Lambda}_{i}$. The structure of the loading matrix implies that some of the variables are allowed to have a contemporaneous relationship with the nominal interest rate, i.e. non-zero elements of $\Psi$.

We introduce time variation into the model by allowing for drift in the coefficients and the error covariance matrix of the transition equation. An alternative specification is to model the time variation associated with the factor loadings ( $\Lambda$ and $\Psi$ ) (see Del Negro and Otrok, 2008). However, Bayesian model selection criteria (specifically, the deviance information criterion) strongly support time variation in the parameters and variances of the transition equation rather than in the factor loadings and the variances of the idiosyncratic components. ${ }^{6}$ These model selection criteria also support setting the number of factors equal to three. As described in the online appendix, further support for three factors comes from the application of the Bai and $\mathrm{Ng}(2002) I C_{1}$ criterion to our dataset.

\footnotetext{
${ }^{4}$ Note that these papers are essentially a generalization of the dynamic factor model used in Kose, Otrok, and Whiteman (2003).

${ }^{5}$ In a recent contribution, Korobilis (2011) proposes a time-varying FAVAR, where the factors are estimated via principal components. In contrast, our paper uses a complete likelihood-based approach.

${ }^{6}$ Specifically, we conduct a model comparison exercise along two dimensions of the model. We compare our benchmark specification against (1) a fixed-coefficient FAVAR, and (2) a FAVAR that incorporates time variation in the factor loading matrix $\bar{\Lambda}_{i}$ and stochastic volatility in the variance of the idiosyncratic components. The results are reported in Table 1 in the not-for-publication appendix (available at: http://www.bankofcanada.ca/author/christianebaumeister).
} 
The transition equation of the system is a time-varying VAR model of the following form

$$
Z_{t}=\delta_{t}+\sum_{l=1}^{L} \phi_{l, t} Z_{t-l}+v_{t}
$$

where $Z_{t}=\left\{F_{t}^{1}, F_{t}^{2}, F_{t}^{3}, R_{t}\right\}$ and the lag length $L=2 .^{7}$

Following Cogley and Sargent (2005) and Primiceri (2005) among others, we postulate the following law of motion for the coefficients $\theta_{t}=\left[\begin{array}{ll}\delta_{t} & \phi_{l, t}\end{array}\right]^{\prime}$ :

$$
\theta_{t}=\theta_{t-1}+\eta_{t}
$$

The time-varying covariance matrix of the VAR innovations $v_{t}$ can be factored as

$$
\operatorname{VAR}\left(v_{t}\right) \equiv \Sigma_{t}=A_{t}^{-1} H_{t}\left(A_{t}^{-1}\right)^{\prime}
$$

$H_{t}$ is a diagonal matrix which contains the stochastic volatilities and $A_{t}$ is a lower triangular matrix that models the contemporaneous interactions among the endogenous variables:

$$
H_{t} \equiv\left[\begin{array}{cccc}
h_{1, t} & 0 & 0 & 0 \\
0 & h_{2, t} & 0 & 0 \\
0 & 0 & h_{3, t} & 0 \\
0 & 0 & 0 & h_{4, t}
\end{array}\right] \quad A_{t} \equiv\left[\begin{array}{cccc}
1 & 0 & 0 & 0 \\
\alpha_{21, t} & 1 & 0 & 0 \\
\alpha_{31, t} & \alpha_{32, t} & 1 & 0 \\
\alpha_{41, t} & \alpha_{42, t} & \alpha_{43, t} & 1
\end{array}\right]
$$

with the $h_{i, t}$ evolving as geometric random walks:

$$
\ln h_{i, t}=\ln h_{i, t-1}+\varepsilon_{t}
$$

Along the lines of Primiceri (2005), we postulate that the non-zero and non-one elements of the matrix $A_{t}$ evolve as driftless random walks:

$$
\alpha_{t}=\alpha_{t-1}+\tau_{t}
$$

The specification described by equations (4) to (10) can be used to incorporate a large amount of information about the U.S. economy into the model. In particular, if the factors in equation (4) contain additional information not captured by a three-variable VAR used in studies such as Primiceri (2005), then one might expect policy shocks identified within the current framework to be more robust. Our flexible specification for the transition equation implies that the model accounts for the possibility of structural breaks in the dynamics that characterize the economy and allows the

\footnotetext{
${ }^{7}$ In the not-for-publication appendix we provide evidence that models with more lags display a poorer fit.
} 
monetary authority to continuously update its knowledge about the macroeconomic environment. ${ }^{8}$

The specification of our factor model (barring time variation) is simpler than the structural dynamic factor model (SFM) examined in Forni and Gambetti (2010), which builds on the work in Forni et al. (2000). In the notation of Forni and Gambetti (2010), we make the simplifying assumption that the number of primitive shocks or dynamic factors $u_{t}$ equals the number of static factors $F_{t}$. This simplification enables us to incorporate stochastic volatility in the structural shocks using standard Bayesian estimation methods. Incorporating time variation in the SFM is an interesting topic for future research. Note also that relative to Forni and Gambetti (2010), we treat the federal funds rate as an observed factor. Given that $R_{t}$ is the policy instrument of the Federal Reserve, and changes in $R_{t}$ are highly publicized and observed by economic agents, it can be argued that this assumption is fairly innocuous in the context of our application.

The model described by equations (4) to (10) is estimated using Bayesian methods described in Kim and Nelson (1999a). Details regarding the prior specifications and the estimation and model selection procedures are provided in the not-for-publication appendix.

\subsection{Identification of monetary policy shocks}

To enable structural analysis, we place the interest rate last in the transition equation (5) as in Bernanke et al. (2005) and use this recursive ordering to identify the monetary policy shock as the only shock that does not affect the latent factors in the system within the quarter. It is in principle possible to employ alternative identification schemes within this framework to recover the underlying structural shocks, e.g. short-run restrictions or sign restrictions, that allow for contemporaneous interactions between the monetary policy instrument and macroeconomic variables or factors. A potential problem associated with a recursive identification scheme is that inference could be distorted due to the incompatibility of zero restrictions with the underlying data-generating process postulated in general equilibrium models (see Canova and Pina, 2005). However, the structure of the observation equation (4) in our model implies that any contemporaneous correlation between 'fast-moving' variables (e.g. asset prices) and the policy rate is already accounted for by the factor loadings $\Psi$. In other words, this amounts to removing the component of the factors that is contemporaneously affected by movements in the funds rate. ${ }^{9}$ This implies that a recursive ordering

\footnotetext{
${ }^{8}$ Stock and Watson (2008) examine the forecasting performance for a panel of U.S. data using a factor model allowing for the possibility of a structural break in the model parameters. They report strong evidence of instability in the factor dynamics and factor loadings around 1984. They find that the best forecast performance is obtained by using the full sample estimate of the factors and a sub-sample estimate of the coefficients of the forecasting equation. The focus of this paper differs from Stock and Watson's (2008) work in two respects. First, we allow for the possibility of drift in the VAR model parameters and for stochastic volatility. Second, our focus is to gauge the extent of time variation rather than evaluating the performance of a fixed-coefficient model when the true data-generating process is characterized by parameter shifts.

${ }^{9}$ A classification of the data series according to their speed of adjustment to interest rate movements can be found in the not-for-publication appendix.
} 
(with the interest rate placed last) can be used in the transition equation.

We calculate the impulse responses $\Delta_{t}$ of $F_{t}^{K}$ and $R_{t}$ to the monetary policy shock for each quarter. The shock is normalized such that it increases the federal funds rate by 100 basis points at each date in the sample to make the responses comparable over time. With these in hand, the timevarying impulse responses of each underlying variable can be easily obtained using the observation equation (4) of the model. That is, the impulse responses $\Delta_{t}$ of $X_{1, t}, \ldots, X_{N, t}$ are computed as:

$$
\left(\begin{array}{c}
\Delta_{t}^{X_{1, t}} \\
\cdots \\
\cdots \\
\Delta_{t}^{X_{N, t}} \\
\Delta_{t}^{R_{t}}
\end{array}\right)=\left(\begin{array}{cccc}
\Lambda^{11} & \Lambda^{12} & \Lambda^{13} & \Psi^{11} \\
\cdots & \cdots & \cdots & \cdots \\
\cdots & \cdots & \cdots & \cdots \\
\cdots & \cdots & \Lambda^{N 3} & \Psi^{N 1} \\
0 & 0 & 0 & 1
\end{array}\right)\left(\begin{array}{c}
\Delta_{t}^{F_{t}^{1}} \\
\Delta_{t}^{F_{t}^{2}} \\
\Delta_{t}^{F_{t}^{3}} \\
\Delta_{t}^{R_{t}}
\end{array}\right)
$$

Given the presence of time-varying parameters in the transition equation, computation of impulse responses has to take into account the possibility of parameter drift over the impulse response horizon. Therefore, following Koop et al. (1996), we define the impulse response functions at each date as

$$
\Delta_{t+k}=E\left(Z_{t+k} \mid \Xi_{t}, Z_{t-1}, \mu_{M P}\right)-E\left(Z_{t+k} \mid \Xi_{t}, Z_{t-1}\right)
$$

where $\Xi_{t}$ denotes all the parameters and hyperparameters of the VAR at time $t$, and $k$ is the horizon under consideration. Equation (12) states that the impulse response functions are calculated as the difference between two conditional expectations. The first term in equation (12) denotes a forecast of the endogenous variables conditioned on a monetary policy shock $\mu_{M P}$. The second term is the baseline forecast, i.e. conditioned on the scenario where the monetary policy shock equals zero. The conditional expectations in (12) are computed via Monte Carlo integration for 500 replications of the Gibbs sampler. Details on the Monte Carlo integration procedure can be found in Koop et al. (1996).

\subsection{Data}

The dataset consists of a balanced panel of quarterly observations on 138 U.S. macroeconomic and financial time series spanning the period from 1960Q1 to 2008Q3, ${ }^{10}$ which cover a broad range of measures of real activity and income, employment, asset prices, interest rates and spreads, exchange rates, price indices and money aggregates. We also include a set of forward-looking indicators like consumer expectations, commodity prices, orders and inventories that should capture signals of the future course of the economy as well as inflationary pressures to which the monetary authority might react pre-emptively. All the series have been obtained from the Bureau of Economic

\footnotetext{
${ }^{10}$ The first ten years are used as a training sample to calibrate our priors.
} 
Analysis (BEA), the Bureau of Labor Statistics (BLS), the U.S. Bureau of the Census and the FRED database. They provide a comprehensive description of the state of the economy containing indicators that are commonly analyzed by a central bank in the monetary policy decision process. ${ }^{11}$

This macroeconomic information set has been augmented by a large panel of disaggregate price and quantity series for a wide range of consumer expenditure categories obtained from the National Income and Product Accounts (NIPA) published by the BEA. We collect data at the highest level of disaggregation and only if observations for one category were missing for the time span we consider, we moved to the next level of aggregation and hence, excluded the sub-categories to avoid double-counting. The remaining sectoral price and volume series are the same as in Boivin et al. (2009) amounting to 190 disaggregated deflator series for personal consumption expenditures (PCE) and the corresponding series on real consumption to which we add price and quantity data for overall PCE, durable and nondurable goods, and services. In total, our dataset includes the effective federal funds rate as the monetary policy instrument and 592 aggregate and disaggregate time series from which we extract the common factors. Data that are available on a monthly basis have been converted to quarterly frequency by taking monthly averages. The variables have been appropriately transformed to induce stationarity and have been demeaned and standardized before estimation. $^{12}$

\section{Results}

\subsection{Aggregate responses to a monetary policy shock}

Before moving to the sectoral level, it is instructive to examine the responses of key U.S. macroeconomic variables to a monetary policy shock that have received most attention in previous studies. Figure 1 displays the estimated (cumulated) impulse responses of aggregate real activity measures and consumer prices to a monetary policy contraction. The left panels of the figure show the median responses in each quarter. The two middle panels compare the responses in 1975Q1 and 2008Q1 as two representative dates of the sample period. The last column considers the relative importance of time variation in impulse responses following the approach by Cogley et al. (2010). In particular, it plots the joint posterior distribution of the cumulated responses at the one-year horizon with values for 1975Q1 plotted on the x-axis and those for 2008Q1 on the y-axis. Shifts of the distribution away from the 45-degree line indicate a systematic change across time.

\footnotetext{
${ }^{11}$ Ideally, the assessment of central bank behavior would rely only on information that was available at the time of policymaking i.e. real-time data as opposed to fully revised ones. However, Bernanke and Boivin (2003) provide compelling evidence that this distinction makes little difference given the latent nature of the factors; what matters most, is the variety of data included in the information set.

${ }^{12} \mathrm{~A}$ detailed description of the data sources and transformations is available in the not-for-publication appendix.
} 
Figure 1 illustrates that a 1\% increase in the federal funds rate reduces the level of real GDP by around $0.5 \%$ at a horizon of two years in more recent times, which is about half the magnitude relative to the earlier part of the sample. Comparable results are obtained for the evolution of the employment responses. These results are in line with Boivin and Giannoni (2006) who report a decline in the effect of policy shocks on real activity indicators after 1980. The last column of Figure 1 provides some indication that the milder reaction of real GDP and employment in more recent times is a non-negligible feature at the one-year horizon since for both measures at least $75 \%$ of the joint distribution lies above the 45-degree line. The evidence for time variation is less clear-cut at longer horizons because of the considerable uncertainty surrounding the median estimates.

The last row of Figure 1 displays the responses of consumer prices. After an unexpected monetary policy shock of 100 basis points, the price level fell by around $0.4 \%$ in the long run during the 1970s, while it currently stabilizes at a level of $1 \%$ below baseline. Boivin and Giannoni (2006) instead find that the CPI response dampens in the Great Moderation period. Due to the initial sluggishness of the price response, the evidence of systematic shifts at the one-year horizon is blurred. The most interesting result is however, that none of the aggregate price measures exhibits a price puzzle. These results support the analysis of Castelnuovo and Surico (2010) who argue that the price puzzle in structural VARs may be a symptom of omitted variable bias that may arise when the Taylor principle is violated. In particular, they show that when the economy is operating under indeterminacy, an additional unobserved variable characterizes the dynamics of the economy. The factors included in our model summarize a large amount of information that may proxy this latent variable. The fact that the price puzzle is absent throughout the sample lends support to this idea (see also Bernanke et al., 2005).

\subsection{Disaggregate price and quantity responses}

In this section, we shed some light on the evolution of disaggregate price and quantity responses over time since movements in relative prices determine the extent to which monetary policy impulses have real effects. If all individual prices were to adjust rapidly and by similar amounts to monetary disturbances, then policy actions would only have moderate and short-lived effects on real economic activity. Knowing how price dynamics differ across goods and services that are part of household consumption expenditures helps understanding the monetary transmission mechanism at the disaggregate level and thus provides valuable insights to policymakers since aggregate price measures are not necessarily the most reliable guide for the conduct of monetary policy. 


\subsubsection{Impulse responses}

Figure 2, panel A displays the median impulse response functions of the individual components of the personal consumption expenditure deflator and the corresponding real quantities after a contractionary monetary policy shock of 100 basis points at our two representative points in time: 1975Q1 and 2008Q1. As a reference, we have also plotted the median responses of the aggregate price and real consumption measures along with the $16^{\text {th }}$ and $84^{\text {th }}$ percentiles of the posterior distribution (red lines) as well as the unweighted average of the disaggregate price and quantity responses (black stars). While the mean of the sectoral price and quantity responses closely tracks the path of the aggregate indices, lying on or within the error bands at all horizons, there is widespread heterogeneity in their adjustment dynamics at the disaggregate level in terms of the degree of responsiveness and direction. In contrast to 1975 where almost half of the individual prices rise permanently following an unexpected monetary tightening, in 2008 we observe that the cross-sectional distribution of price reactions is compressed and shifts downward with the majority of items responding negatively. Instead, the heterogeneous dynamics of the quantity responses do not exhibit such a noticeable change with regard to the range of responses across time in the long run, but the distribution moves upward implying that the reduction of consumption volumes is more short-lived. In fact, aggregate PCE consumption as well as most of the sectoral quantities of goods and services show a substantial and more persistent fall in 1975, while the reactions are more muted in 2008. Only a few categories of goods and services experience an increase in demand despite the interest rate rise.

To get a better sense of changes in the pattern of the individual price and quantity responses over time, Figure 2, panel B depicts the evolution of the disaggregate, aggregate and mean reactions over the whole sample period 4 and 12 quarters after the restrictive monetary policy action. A considerable fraction of price responses displays a price puzzle during the 1970s, especially at short horizons, which attenuates as time progresses and from the mid-eighties onwards many of the sectoral prices decline in response to a negative monetary shock. In comparison to the price responses, there seems to be less evidence for time variation in the reaction of real quantities, with a large share of individual goods' and services' consumption volumes falling after an unexpected increase in the fed funds rate.

The slightly stronger reduction in consumption quantities in the early part of the sample might be linked to higher individual prices. We follow Boivin et al. (2009) to get an idea of this interaction between sectoral quantity and price responses conditional on a monetary policy shock over time. Figure 3 shows two scatter plots of price-volume combinations for all PCE items one year after the monetary innovation, together with the cross-sectional regression line for 1975Q1 and 2008Q1. In line with Boivin et al. (2009), we find that sectors where prices react the most, quantities adjust the least. Over time two things happen. First, the cloud of pairs shifts to the lower left quadrant 
implying that more disaggregate price and consumption responses are negative in the more recent past. Second, the regression line flattens indicating that consumption volumes get less responsive relative to prices. In the lower left graph of Figure 3, we plotted the estimated slope coefficients which show how the price-volume relationship evolves over time. The gradual decline of the slope coefficient over the sample period reveals that nominal adjustments to monetary shocks take place more and more by prices than by quantities. Thus, in more recent times, sectors on average absorb contractionary monetary policy actions by adapting sales prices rather than production volumes. This finding at the disaggregate level is in line with the decline in real effects of monetary surprises observed for economy-wide activity measures and the greater sensitivity of aggregate price responses.

\subsubsection{Cross-sectional distribution of prices}

Another way of summarizing the information of the effects of monetary policy shocks on the spread of disaggregate price responses is by looking at their entire distribution across items. Figure 4, panel A shows the estimated smoothed densities of sectoral prices for the years 1975 and 2008 at selected horizons in the upper part, and the distributions in four different years 4 and 16 quarters after the monetary innovation in the lower part. The evolution of the cross-sectional distribution in the quarters following the shock illustrates how a monetary policy disturbance propagates through the individual prices of goods and services inducing changes in relative prices which in turn affect the real economy.

We observe a gradual increase in the dispersion over the first years which highlights differences in speed and magnitude of price adjustments. While the distribution of disaggregate price responses in 1975 widens around zero as the horizon lengthens, it gradually shifts to the right of the origin in 2008 which implies that now more individual prices decline after a contractionary shock albeit with some delay. Also the size of the shift is greater in more recent times confirming the evidence at the aggregate level of a greater responsiveness of prices to monetary impulses. As is evident from a comparison of the evolution of the cross-sectional densities at horizons 4 and 16 at different points in time, there is a gradual transition from mainly positive to more negative responses both over the horizon and the sample.

A more concise way of capturing the evolutionary pattern of the cross-sectional distribution for all horizons over the whole sample period is by describing the densities by means of their moments which are depicted in Figure 4, panel B. During the first years of the sample, the median of the distribution falls only slightly below zero over the horizon confirming our evidence that the price responses of single PCE components are spread around the origin with almost half of them still being in the positive range 20 quarters after the shock. Across time and horizons the median gets 
more and more negative pointing to a considerable leftward shift of the sectoral density. The standard deviation captures the dispersion of relative price movements induced by the contractionary monetary policy shock. Both measures rise steeply over the first ten quarters and then stabilize at this level as the horizon extends further. The widening of the price dispersion is symptomatic of the fact that price reactions are not uniform across PCE categories. The spread of the density is remarkably stable at around $0.75 \%$ during the 1970 s and 1980 s but decreases steadily from the early nineties onwards. The relative price dispersion is very persistent reaching a permanently higher level over the horizon considered here, but moderates slightly along the time line.

\subsubsection{Heterogeneity of price responses}

The dispersion across responses of individual prices to monetary policy impulses reinforces the idea that various channels of monetary transmission are at work in different sectors that differ in strength and importance, i.e. industries respond differently to monetary shocks depending on which channel they are most sensitive to. Hence, it might be of interest to explore which sectors contribute most to the dispersion and are more prone to displaying a price puzzle by grouping the price and quantity responses into different categories. We first organize the responses into three major sub-categories - durables, nondurables, and services - which are depicted in Figure 5, panel A, for the entire sample period.

We report the dynamic effects 8 quarters after the monetary policy innovation since this strikes a good balance between the short run (the price puzzle dying out) and the long run (the widening of the dispersion). As emerges from the graphs, durables are most sensitive to interest rate innovations and react in the expected way showing a considerable fall in consumption volumes and a decline in the price level after the 1970 period with the exception of two items. Durable goods also contribute the least to the dispersion of sectoral prices since individual impulse responses are closely aligned. Instead, nondurable goods and to some extent services account for a large share of cross-sectional heterogeneity since price responses are widely dispersed covering a broad range of positive and negative values. Supply-side effects appear to play an important role in the propagation of monetary impulses to service categories like transportation, household operation and recreational activities, as can be seen from Figure 5, panel B, where we group disaggregate responses according to more detailed product classes. However, the positive price responses in these sectors are accompanied by a relatively large decrease in quantities purchased providing some evidence for the cash-flow argument advanced by Stiglitz (1992). Responses belonging to the product groups vehicles, clothes as well as food and furniture for most of their components rather comply with the demand channel of monetary transmission since the early eighties. 


\subsection{Sensitivity analysis}

The FAVAR model in equations (4) and (5) offers a flexible specification that can be used to examine changes in the monetary transmission mechanism. However, the specification of the observation equation of the model involves a number of simplifying assumptions.

First, we assume that the idiosyncratic shocks are uncorrelated across time and across cross sections. That is, we estimate an exact factor model rather than considering an approximate factor model which allows for non-spherical and serially-correlated idiosyncratic components (see Chamberlain and Rothschild, 1983). Doz et al. (2007) have shown recently that even when the true model has serially-correlated and non-spherical idiosyncratic errors, the latent factors can be estimated consistently by maximum likelihood (as the number of cross sections and time periods go to infinity) using a mis-specified model which ignores both cross-sectional and serial correlation. This result is important in our application which is based on likelihood techniques and applied to a panel with a large cross-section and time dimension.

Our benchmark specification also assumes that the idiosyncratic components are homoscedastic. In this section, we relax this assumption and allow the diagonal elements of $\Sigma^{R}$ to follow a stochastic volatility process:

$$
\ln \left(\Sigma_{i, t}^{R}\right)=\ln \left(\Sigma_{i, t-1}^{R}\right)+\zeta_{t}
$$

Figure 6 plots the time path of some key impulse responses derived from this extended model using the recursive identification scheme discussed in section 2.2. The evolution of the CPI response is similar to the benchmark case. As in the benchmark specification, the negative response is larger in the post-1985 period. The GDP response is also similar to the benchmark result but shows somewhat stronger time variation than in the baseline model. The second panel shows the evolution across time of the median and standard deviation of the responses of diaggregate prices (at the 2-year horizon). As in the benchmark case, the median response becomes more strongly negative after 1980. However, the time path is estimated to be more volatile than in the benchmark possibly reflecting the fact that the extended model contains substantially more free parameters and the responses are estimated less precisely. Similarly, while the standard deviation of diaggregate prices also declines over time, the path is more volatile than in the benchmark model. The median and standard deviation of quantity responses shown in the last panel of the figure show the same pattern as obtained with the baseline specification - i.e. the median response becomes smaller over time, while the standard deviation declines. Note, however, that we find that the changes during the 1970s occur faster than in the benchmark. However, consistent with the benchmark results, both the median and standard deviation of the quantity responses are smaller in magnitude over the post-2000 period. Overall, these results broadly support the pattern of time variation in key variables obtained with the benchmark model. 


\section{Explaining sectoral price dynamics}

Two aspects of our empirical results stand out: first, the existence of a price puzzle in the short run at a high level of disaggregation; and second, considerable variation in price responses both across the panel of individual goods and services, and over time. While a price puzzle is absent for the aggregate PCE deflator, the finding of a price puzzle at the disaggregate level over the short horizon warrants further investigation. Despite the fact that the price puzzle attenuates considerably over time, it does not vanish for all categories of goods and services contained in the personal consumption basket.

The conventional explanation of omission of relevant variables from the information set of the policymaker does not seem plausible in our data-rich environment (see Bernanke et al. 2005). Arguably, we have included a large amount of macroeconomic indicators and sectoral conditions, which a central bank takes into consideration when making policy decisions. Therefore, misspecification alone is highly unlikely to account for the positive responses of some disaggregate prices. Furthermore, we allow for time variation thereby taking account of the observed instability in macroeconomic time series due to changes in the economic environment as documented in the Great Moderation literature.

If mis-specification and other biases can be excluded as potential explanations for the sectoral price puzzles, our evidence provides a case for the price puzzle as not being a "puzzle" at the disaggregate level, but rather a distinctive feature of sectoral dynamics. In what follows, we examine several explanations for our empirical findings by means of simulation experiments using a multisector sticky-price model.

\subsection{A multi-sector sticky-price dynamic stochastic general equilibrium model}

We use the multi-sector sticky-price DSGE model by Nakajima et al. (2010) to explore the links between disaggregate price responses and aggregate macroeconomic shocks. Following Carvalho (2006), Nakajima et al. (2010) introduce sectoral heterogeneity into the DSGE model of Erceg et al. (2000). In this model, firms display heterogeneous price-setting behavior such that firms in each sector face a different (Calvo) probability $\lambda_{k}$ of resetting prices optimally. ${ }^{13}$ When firm $j$ in sector

\footnotetext{
${ }^{13}$ Here we mainly illustrate the firm's pricing problem; the interested reader is referred to Erceg et al. (2000), Carvalho (2006), and Nakajima et al. (2010) for the details of the model.
} 
$k$ sets its price $X_{k j, t}$, firm $k j$ solves

$$
\begin{gathered}
\max E_{t} \sum_{s=0}^{\infty} Q_{t, t+s}\left(1-\lambda_{k}\right)^{s}\left[X_{k j, t} Y_{k j, t+s}-W_{k j, t+s} N_{k j, t+s}\right] \\
\text { s.t. } Y_{k j, t+s}=N_{k j, t+s} \text { and } Y_{k j, t+s}=\left(\frac{X_{k j, t}}{P_{t+s}}\right)^{-\epsilon} Y_{t+s}
\end{gathered}
$$

where $Y_{k j, t+s}, W_{k j, t+s}$, and $N_{k j, t+s}$ are the firm's output, nominal wage, and labor input respectively; $Q_{t, t+s}, P_{t+s}$, and $Y_{t+s}$ are the stochastic discount factor, the aggregate price level, and aggregate output; and $\epsilon$ is the elasticity of substitution between differentiated products. Solving the firm's problem in (14) yields the following first order condition:

$$
X_{k j, t}=\frac{\epsilon}{1-\epsilon} \frac{E_{t} \sum_{s=0}^{\infty} Q_{t, t+s}\left(1-\lambda_{k}\right)^{s} P_{t+s}^{\epsilon} Y_{t+s} W_{k j, t+s}}{E_{t} \sum_{s=0}^{\infty} Q_{t, t+s}\left(1-\lambda_{k}\right)^{s} P_{t+s}^{\epsilon} Y_{t+s}}
$$

The distribution of future wages, $W_{k j, t+s}$, conditional on information at time $t$, is the same for all firms in sector $k$, and therefore all firms in sector $k$ choose the same optimal price $X_{k, t}$. Thus, the sectoral price under Calvo-type price stickiness can be written as:

$$
P_{k, t}=\left[\lambda_{k} X_{k, t}^{1-\epsilon}+\left(1-\lambda_{k}\right) P_{k, t-1}^{1-\epsilon}\right]^{\frac{1}{1-\epsilon}}
$$

The household's consumption and wage-setting problems are identical to the model by Erceg et al. (2000). Essentially, the heterogeneity assumption results in different Phillips curves for each of the $N$ sectors in an otherwise standard New Keynesian model. As pointed out by Carvalho (2006), heterogeneity in price stickiness leads monetary shocks to have larger and more persistent real effects than in identical-firm economies with similar degrees of nominal and real rigidities.

For the baseline simulation, we use the same set of parameter values as described in Nakajima et al. (2010), where the frequency of price changes across different sectors $(N=134)$ is based on the results reported by Nakamura and Steinsson (2008).

\subsection{The sectoral price puzzles and the cost channel}

Heterogeneity itself can not explain the price puzzle at the disaggregate level. There are a number of studies that suggest that the cost channel of monetary policy is an important part of the monetary transmission mechanism. ${ }^{14}$ Barth and Ramey (2001) argue that in view of financial market frictions,

\footnotetext{
${ }^{14}$ For instance, Christiano et al. (2005) suggest that when a cost channel exists alongside sticky wages, consumer prices in the aggregate can initially rise in response to a contractionary monetary policy shock. Empirically, several papers argue for the presence of a cost channel (e.g. Ravenna and Walsh, 2006 and Chowdhury et al., 2006).
} 
firms experience an unanticipated increase in the federal funds rate as a cost-push shock and cope with it by passing the increased production costs on to consumers, at least in the short run. In a similar vein, Stiglitz (1992) suggests that in an imperfectly competitive environment firms tend to raise their prices following a monetary contraction in order to increase their cash flows momentarily before sales recede. However, this comes at the expense of facing greater demand reductions in the future. These pricing strategies will depend on the degree of market power firms possess, which are likely to differ across sectors. Nakajima et al. (2010) introduce the cost channel of monetary policy by assuming that firms must borrow from financial intermediaries in advance to pay the wage bill (as a proxy for working capital). Therefore, changes in the nominal interest rate have a direct impact on firms' marginal cost of production such that

$$
M C_{t}=R_{t} \frac{W_{t}}{Z_{t}}
$$

where $R_{t}$ and $Z_{t}$ are respectively the nominal interest rate and the aggregate of technology common to all firms. The presence of the cost channel generates asymmetric disaggregate price responses to a monetary policy shock. ${ }^{15}$

Figure 7 shows the sectoral price responses of Nakajima et al.'s multi-sector model after a contractionary monetary policy shock. We split the responses of sectoral prices into "flexible firms" and "inflexible firms" according to the frequency of price changes using the median frequency as the cut-off point. Flexible firms correspond to sectors that adjust their prices more frequently with durations less than 4.5 quarters. On the other hand, inflexible firms belong to sectors with durations of more than 4.5 quarters. The left-hand side panels plot the disaggregate sectoral price responses of the flexible and inflexible firms, while the right-hand side panels display the aggregate price response and the share of positive responding items at different horizons. ${ }^{16}$

The first observation is that there is a temporary increase in the aggregate price level immediately after a monetary policy tightening. Following an increase in the interest rate caused by a monetary shock, real marginal costs decline because wages fall as a result of declining labor demands. This traditional channel of monetary policy - the demand-side effect - will induce firms to lower their prices. However, with the presence of the cost channel, the increase in the nominal interest rate acts as a cost-push shock pushing up the marginal cost of firms - the supply-side effect. However, from the disaggregate price responses it becomes evident that not all firms increase their prices.

Generally, more flexible firms increase their prices on impact in response to the higher marginal

\footnotetext{
${ }^{15}$ Nakajima et al. (2010) also include heterogeneity in real rigidities across sectors to help weaken the cross-sectional correlations between the disaggregate price responses and the frequency of price adjustment. Here, we focus on the specification with the cost channel of monetary policy.

${ }^{16}$ The model's calibration assumes that each sector receives equal weight in the consumption basket.
} 
cost because of their ability to adjust prices more frequently now and in the future. On the other hand, less flexible firms are more likely to maintain or lower prices reflecting their inability to adjust prices in the near future once they reset their prices today. Thus, the existence of a price puzzle in the short run at a high level of disaggregation in our empirical results is consistent with the presence of the cost channel of monetary policy combined with heterogeneous pricing behavior across different sectors.

\subsection{Changes in disaggregate price dynamics over time}

Another key empirical finding is that both the price puzzle and the dispersion of individual price responses appear to attenuate considerably over our sample period, although the price puzzle does not vanish for all categories of goods and services. Here we present two simulation experiments using the multi-sector model outlined above to explore which structural changes may explain these observed empirical findings over time. However, the two structural changes illustrated here are by no means an exhaustive list of structural features that may be compatible with our empirical results.

\subsubsection{Sensitivity to the cost channel}

Barth and Ramey (2001) show by means of a sample split using industry-level data that the cost-side channel of monetary transmission dominated in many industries in the period before 1980 and weakens thereafter. This observation is consistent with our empirical evidence. Barth and Ramey argue that banking and credit regulations in the earlier period, which limited the scope of lenders and borrowers to respond to sudden monetary contractions, may have allowed monetary policy to restrict the availability of working capital. In the later period, deregulation and financial innovations allowed banks and firms to gain access to alternative sources of funds, thereby potentially dampening the cost channel of monetary policy.

We investigate the importance of this channel over time by varying the sensitivity of the firms' marginal cost to the nominal interest rate (from the baseline specification of 1). Figure 8, panel A plots the median and standard deviation of the individual price and quantity responses simulated from the model at horizons of one quarter, one year and two years after the monetary policy shock. For ease of comparison, panel B reports the empirical counterparts over time. As the sensitivity to the cost channel decreases, the median price responses decline across all horizons, and at the same time, the decrease in the median quantity responses gets smaller. Both the standard deviation of price and quantity responses also decline, which indicates that the dispersion of these responses becomes smaller. These observations are consistent with our empirical results, which suggests that the cost channel of monetary policy has weakened over time. 
Intuitively, the cost channel interacts with the heterogeneous pricing behavior of firms that amplifies the heterogeneity in the price and quantity responses. In the absence of the cost channel, all firms will respond to the monetary tightening by reducing their prices, which weakens the "strategic-complementarities" effects in heterogeneous price setting as described in Carvalho (2006). That is, pricing decisions of firms in sectors with more frequent price changes are also influenced by the existence of slower-adjusting sectors, since the former do not want to set prices that will deviate too much from the aggregate price in the future. This in part explains the reduction in the dispersion of the sectoral price and quantity responses with the decline in importance of the cost channel.

\subsubsection{Degree of wage flexibility}

Using microdata from the Current Population Survey, Champagne and Kurmann (2010) show that there has been a substantial increase in the volatility of wages relative to output volatility in the U.S. during the past 25 years. They argue that this increase in relative volatility is predominantly due to an increase in the flexibility of wages across different groups of workers. At the same time, this increase in wage flexibility generates a considerable decrease in the magnitude of business cycle fluctuations, which provides a new explanation for the Great Moderation. In addition, Rabanal (2006) shows that the importance of the cost channel of monetary policy depends on the degree of wage flexibility. Here we explore the role of wage stickiness on the heterogeneous firms' responses to a contractionary monetary policy shock. Figure 8, panel $\mathrm{C}$ plots the median and standard deviation of the price and quantity responses at horizons of one quarter, one year and two years, for a varying degree of wage stickiness in the model. As before, a decline in wage stickiness is consistent with a smaller price puzzle and a smaller dispersion in the sectoral price and quantity responses as uncovered in our empirical analysis.

The intuition for this result is that when wages are very sticky, the possibility for downward adjustment following a monetary policy shock decreases. The supply-side effect (the cost channel) will play a larger role in keeping firms' marginal costs higher. Consequently, more firms choose to increase their prices which results in a more pronounced price puzzle at the aggregate and disaggregate level. The degree of wage stickiness interacts with sticky prices, which act as another amplification mechanism for the cost channel, and therefore induce larger dispersions in firms' price and quantity responses.

\subsection{Policy implications}

Based on our empirical findings and simulation results from a multi-sector sticky-price model, we find significant evidence in support of models with sectoral heterogeneity that endogenize the 
pricing decisions of firms to account for their strategic behavior. Such extensions yield richer macroeconomic dynamics that better comply with the microeconomic evidence on price-setting behavior.

Given the key role of price-setting behavior in understanding the monetary transmission mechanism, knowing how monetary policy shocks affect sectoral prices and quantities provides the monetary authority with useful information on how to interpret sectoral signals in order to devise appropriate policy reactions. In addition, positive sectoral price responses following a contractionary monetary policy may not be a statistical artifact; instead, they may indicate the existence of important channels at the disaggregate level, such as the cost channel, which are often missing in macroeconomic models employed in policy analysis. For example, Ravenna and Walsh (2006) find important implications of the cost channel for the design of optimal monetary policy.

It is equally important for policymakers to recognize that measures of aggregate inflation can hide disaggregate dynamics and hence, are a poor indicator for pricing behavior at the microeconomic level. In fact, Aoki (2001) stresses the importance of selecting the appropriate goal variables for the conduct of monetary policy given that the behavior of sectoral prices can differ substantially from aggregate indices. In view of this, Carlstrom et al. (2006) propose a two-sector model which includes an interest-rate rule according to which the central bank can react to sectoral inflation rates with different intensities. It appears to be optimal to put different weights on sub-indices of aggregate price measures in policy analysis depending on the underlying pricing behavior of sectors to monetary impulses. Our findings should make policymakers more aware of the importance of heterogeneity and the potentially important compositional effects of monetary policy actions.

\section{Conclusions}

In this paper, we have examined the evolution of the U.S. monetary transmission mechanism over time at both the aggregate and disaggregate level using an extended version of the factor-augmented VAR model proposed by Bernanke et al. (2005). Our empirical framework incorporates information from almost 600 macroeconomic indicators and disaggregate price and quantity variables representing various sectors of the economy. By allowing for time variation in the coefficients and stochastic volatility in the variances of the shocks, we analyze the time-varying dynamic responses to a contractionary monetary policy shock for macroeconomic aggregates and sectoral prices and quantities of personal consumption expenditures. This is important not only to get a better understanding of the behavior of disaggregate prices in response to monetary disturbances, but also to assess the role of price-setting behavior in the propagation mechanism and how this might have altered in response to changes in the macroeconomic environment.

We find no evidence of a price puzzle for any of the aggregate price measures throughout the 
sample period. This suggest that the extra information captured by the factors leads to more robust structural estimates in that it mimics the central bank's practice of examining and reacting to a wide variety of economic indicators. Likewise, accounting for time-varying dynamics might be another important dimension for these findings since it allows the central bank to continuously learn about the state of the economy and adapt its policy behavior accordingly.

However, at the disaggregate level, a considerable portion of sectoral price responses display a price puzzle at short horizons during the 1970s, which decreases however from the early eighties onwards. We also find a shift in the relationship between the responses of prices relative to consumption volumes which tends to suggest that over time nominal adjustment of the economy following a restrictive monetary policy shock increasingly takes place by prices rather than by quantities. This finding at the disaggregate level is in line with the decline in real effects of monetary surprises observed for economy-wide activity measures and the greater sensitivity of aggregate price responses. Apart from considerable heterogeneity in the median responses of prices at the disaggregate level, we also observe important changes in the cross-sectional distribution of responses over the sample period. While the price dispersion diminishes slightly over time, it widens considerably over the forecast horizon and is very persistent in the long run.

To gain a better understanding of these empirical findings, we use a multi-sector DSGE model to investigate the interaction between firms' heterogeneous pricing decision and monetary policy shocks. We find that the presence of the cost channel of monetary policy, which acts as a "costpush" shock following a monetary contraction, is consistent with the price puzzle in the short run at a high level of disaggregation. By means of simulation exercises, we show that the attenuation of disaggregate price puzzles over time can in part be attributed to a decrease in the relevance of the cost channel of monetary policy and lower wage stickiness. Therefore, positive sectoral price responses following a restrictive monetary policy shock may not be a statistical artifact. Instead, they may indicate the existence of important channels at the disaggregate level, which are often missing in macroeconomic models employed in policy analysis. Model extensions in that direction can yield richer macroeconomic dynamics that better comply with the microeconomic evidence on price-setting behavior. Knowing which types of goods are more sensitive to monetary policy actions may not only improve our understanding of how monetary policy disturbances are propagated but also enhance the effectiveness of monetary policy as a tool to stabilize the economy. Future research could therefore be directed towards understanding the interactions between monetary policy objectives and the heterogeneity of disaggregate price responses to macroeconomic disturbances for the design of optimal monetary policy. 


\section{References}

[1] Altissimo, Filippo, Benoît Mojon, and Paolo Zaffaroni. 2009. "Can Aggregation Explain the Persistence of Inflation?" Journal of Monetary Economics, 56: 231-241.

[2] Aoki, Kosuke. 2001. "Optimal Monetary Policy Responses to Relative-Price Changes." Journal of Monetary Economics, 48: 55-80.

[3] Bai, Jushan, and Serena Ng. 2002. "Determining the Number of Factors in Approximate Factor Models." Econometrica, 70: 191-221.

[4] Balke, Nathan, and Mark Wynne. 2007. "The Relative Price Effects of Monetary Shocks." Journal of Macroeconomics, 29: 19-36.

[5] Barth, Marvin J., and Valerie Ramey. 2001. "The Cost Channel of Monetary Transmission." NBER Macroeconomics Annual, 16: 199-239.

[6] Benati, Luca, and Haroon Mumtaz. 2007. "U.S. Evolving Macroeconomic Dynamics: A Structural Investigation." European Central Bank Working Paper 476.

[7] Benati, Luca, and Paolo Surico. 2009. "VAR Analysis and the Great Moderation." American Economic Review, 99: 1636-1652.

[8] Bernanke, Ben, and Jean Boivin. 2003. "Monetary Policy in a Data-Rich Environment." Journal of Monetary Economics, 50: 525-546.

[9] Bernanke, Ben, Jean Boivin, and Piotr Eliasz. 2005. "Measuring the Effects of Monetary Policy: A Factor-Augmented Vector Autoregressive (FAVAR) Approach." Quarterly Journal of Economics, 120: 387-422.

[10] Bils, Mark, and Peter Klenow. 2004. "Some Evidence on the Importance of Sticky Prices." Journal of Political Economy, 112: 947-985.

[11] Blinder, Alan. 1991. "Why Are Prices Sticky? Preliminary Results from an Interview Study." American Economic Review, 81: 89-96.

[12] Boivin, Jean, and Marc Giannoni. 2006. "Has Monetary Policy Become More Effective?" Review of Economics and Statistics, 88: 445-462.

[13] Boivin, Jean, Marc Giannoni, and Ilian Mihov. 2009. "Sticky Prices and Monetary Policy: Evidence from Disaggregated U.S. Data." American Economic Review, 99: 350-384.

[14] Canova, Fabio and, Joaquim Pina. 2005. "What VAR Tell Us About DSGE Models." In: Diebolt, C. and, C. Kyrtsou (eds.), New Trends in Macroeconomics, Springer Verlag. 
[15] Carlstrom, Charles, Timothy Fuerst, Fabio Ghironi, and Kólver Hernández. 2006. "Relative Price Dynamics and the Aggregate Economy." http://copland.udel.edu/ kolver/research/papers/2sec/persistence.pdf.

[16] Carvalho, Carlos. 2006. "Heterogeneity in Price Stickiness and the Real Effects of Monetary Shocks." Frontiers of Macroeconomics, 2: 1-56.

[17] Castelnuovo, Efrem, and Paolo Surico. 2010. "Monetary Policy, Inflation Expectations and the Price Puzzle." Economic Journal, 549: 1262-1283.

[18] Chamberlain, Gary, and Michael Rothschild. 1983. "Arbitrage, Factor Structure, and MeanVariance Analysis on Large Asset Markets." Econometrica, 51: 1281-1304.

[19] Champagne, Julien, and André Kurmann. 2011. "The Great Increase in Relative Volatility of Real Wages in the United States." http://ideas.repec.org/p/lvl/lacicr/1010.html.

[20] Christiano, Lawrence, Martin Eichenbaum, and Charles Evans. 2005. "Nominal Rigidities and the Dynamic Effects of a Shock to Monetary Policy." Journal of Political Economy, 113: 1-45.

[21] Chodhury, Ibrahim, Mathias, Hoffmann, and Andreas Schabert. 2006. "Inflation Dynamics and the Cost Channel of Monetary Transmission." European Economic Review, 50: 955-1016.

[22] Clark, Todd. 2006. "Disaggregate Evidence on the Persistence of Consumer Price Inflation." Journal of Applied Econometrics, 21: 563-587.

[23] Cogley, Timothy, and Thomas J. Sargent. 2005. "Drift and Volatilities: Monetary Policies and Outcomes in the Post WWII U.S." Review of Economic Dynamics, 8: 262-302.

[24] Cogley, Timothy, Giorgio E. Primiceri, and Thomas J. Sargent. 2010. "Inflation-Gap Persistence in the US." American Economic Journal: Macroeconomics, 2: 43-69.

[25] De Graeve, Ferre, and Karl Walentin. 2011. "Stylized (Arte)Facts on Sectoral Inflation." Sveriges Riksbank Working Paper 254.

[26] Del Negro, Marco, and Christopher Otrok. 2008. "Dynamic Factor Models with Time-Varying Parameters: Measuring Changes in International Business Cycles." Staff Reports 326, Federal Reserve Bank of New York.

[27] Doz, Catherine, Domenico Giannone, and Lucrezia Reichlin. 2007. "A Two-Step Estimator for Large Approximate Dynamic Factor Models Based on Kalman Filtering." Journal of Econometrics, forthcoming. 
[28] Erceg, Christopher J., Dale W. Henderson, and Andrew T. Levin. 2000. "Optimal Monetary Policy with Staggered Wage and Price Contracts." Journal of Monetary Economics, 46: 281313.

[29] Forni, Mario, and Luca Gambetti. 2010. "Macroeconomic Shocks and the Business Cycle: Evidence from a Structural Factor Model." http://pareto.uab.es/lgambetti/ForniGambetti4_2_10.pdf.

[30] Forni, Mario, Marc Hallin, Marco Lippi, and Lucrezia Reichlin. 2000. "The Generalized Dynamic Factor Model: Identification and Estimation." Review of Economics and Statistics, 82: $540-554$.

[31] Kim, Chang-Jin, and Charles R. Nelson. 1999a. State-Space Models with Regime Switching. Cambridge: MIT Press.

[32] Kim, Chang-Jin, and Charles R. Nelson. 1999b. "Has the U.S. Economy Become More Stable? A Bayesian Approach Based on a Markov-Switching Model of the Business Cycle." Review of Economics and Statistics, 81: 608-616.

[33] Koop, Gary, Hashem Pesaran, and Simon Potter. 1996. "Impulse Response Analysis in Nonlinear Multivariate Models." Journal of Econometrics, 74: 119-147.

[34] Korobilis, Dimitris. 2011. "Assessing the Transmission of Monetary Policy Shocks Using Dynamic Factor Models." Oxford Bulletin of Economics and Statistics, forthcoming.

[35] Kose, M. Ayhan, Christopher Otrok, and Charles H. Whiteman. 2003. "International Business Cycles: World, Region, and Country-Specific Factors." American Economic Review, 93: 12161239 .

[36] Lastrapes, William. 2006. "Inflation and the Distribution of Relative Prices: The Role of Productivity and Money Supply Shocks." Journal of Money, Credit, and Banking, 38: 21592198.

[37] Lubik, Thomas, and Frank Schorfheide. 2004. "Testing for Indeterminacy: An Application to U.S. Monetary Policy." American Economic Review, 94: 190-217.

[38] McConnell, Margaret, and Gabriel Pérez-Quirós. 2000. "Output Fluctuations in the United States: What Has Changed Since the Early 1980's?" American Economic Review, 90: 14641476 .

[39] Mumtaz, Haroon, and Paolo Surico. Forthcoming. "Evolving International Inflation Dynamics: World and Country-Specific Factors." Journal of the European Economic Association. 
[40] Nakajima, Jouchi, Nao Sudo, and Takayuki Tsuruga. 2010. "How Well Do the Sticky Price Models Explain the Disaggregated Price Responses to Aggregate Technology and Monetary Policy Shocks?" IMES Discussion Paper Series 2010-E-22.

[41] Nakamura, Emi, and Jón Steinsson. 2008. "Five Facts about Prices: A Reevaluation of Menu Cost Models." Quarterly Journal of Economics, 123: 1415-1464.

[42] Primiceri, Giorgio. 2005. "Time Varying Structural Vector Autoregressions and Monetary Policy." Review of Economic Studies, 72: 821-852.

[43] Rabanal, Pau. 2007. "Does Inflation Increase after a Monetary Policy Tightening? Answers Based on an Estimated DSGE Model." Journal of Economic Dynamics and Control, 31: 906216.

[44] Ravenna, Federico, and Carl E. Walsh. 2006. "Optimal Monetary Policy with Cost Channel." Journal of Monetary Economics, 53: 199-216.

[45] Sims, Christopher, and Tao Zha. 2006. "Were There Regime Switches in U.S. Monetary Policy?" American Economic Review, 96: 54-82.

[46] Stiglitz, Joseph. 1992. "Capital Markets and Economic Fluctuations in Capitalist Economies." European Economic Review, 36: 269-306.

[47] Stock, James, and Mark W. Watson. 2008. "Forecasting in Dynamic Factor Models Subject to Structural Instability." In: Castle, Jennifer, and Neil Shephard (eds.), The Methodology and Practice of Econometrics, A Festschrift in Honour of Professor David F. Hendry, Oxford: Oxford University Press. 

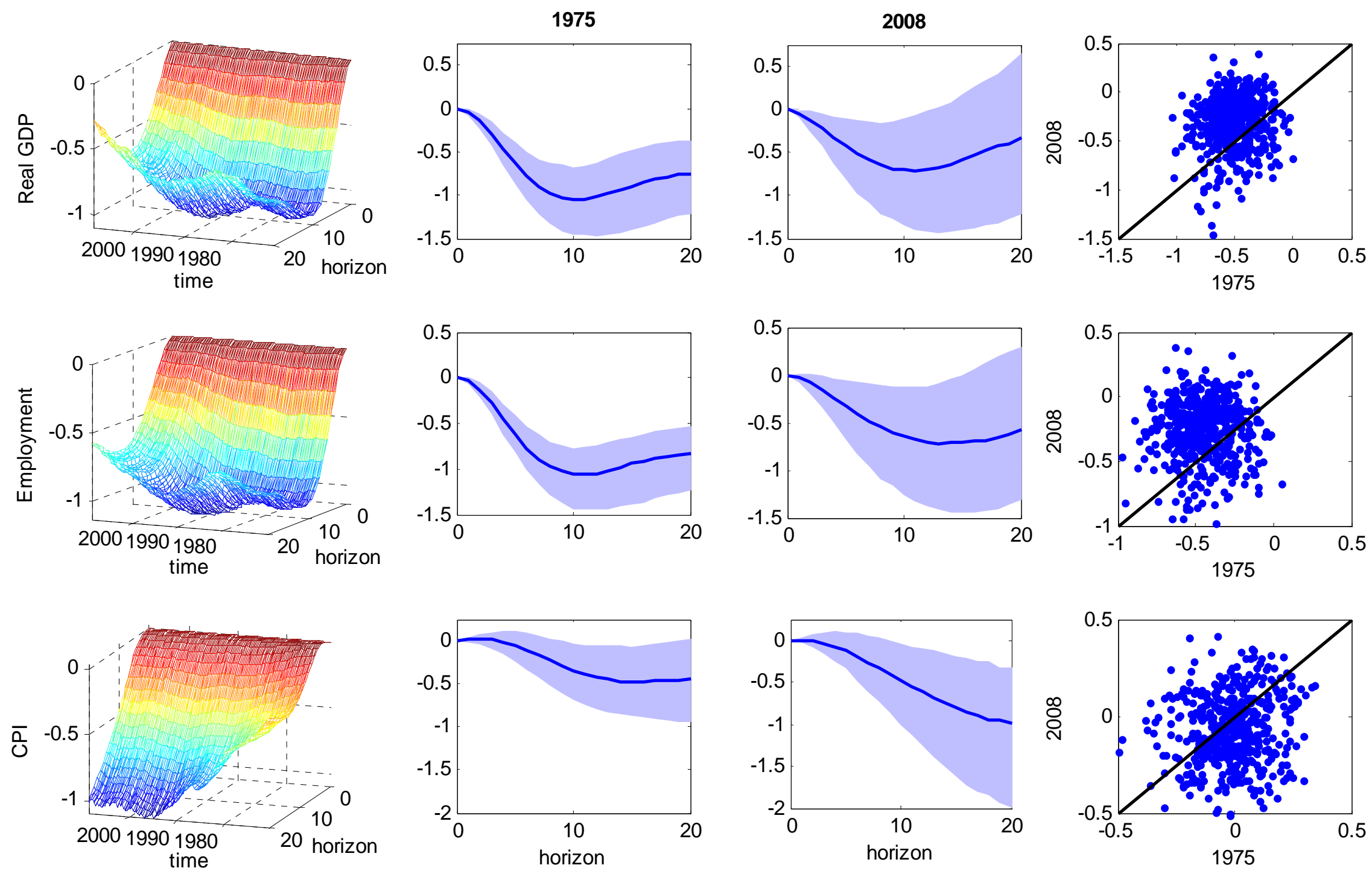

Figure 1: Time-varying median impulse response functions of selected aggregate variables at each point in time (first column) and in 1975Q1 and 2008Q1 (second and third columns) with $16^{\text {th }}$ and $84^{\text {th }}$ percentiles (shaded areas) to a $1 \%$ increase in the funds rate and joint distribution of the cumulated responses 1 year after the monetary policy shock in 1975Q1 and 2008Q1 (fourth column). 
PANEL A
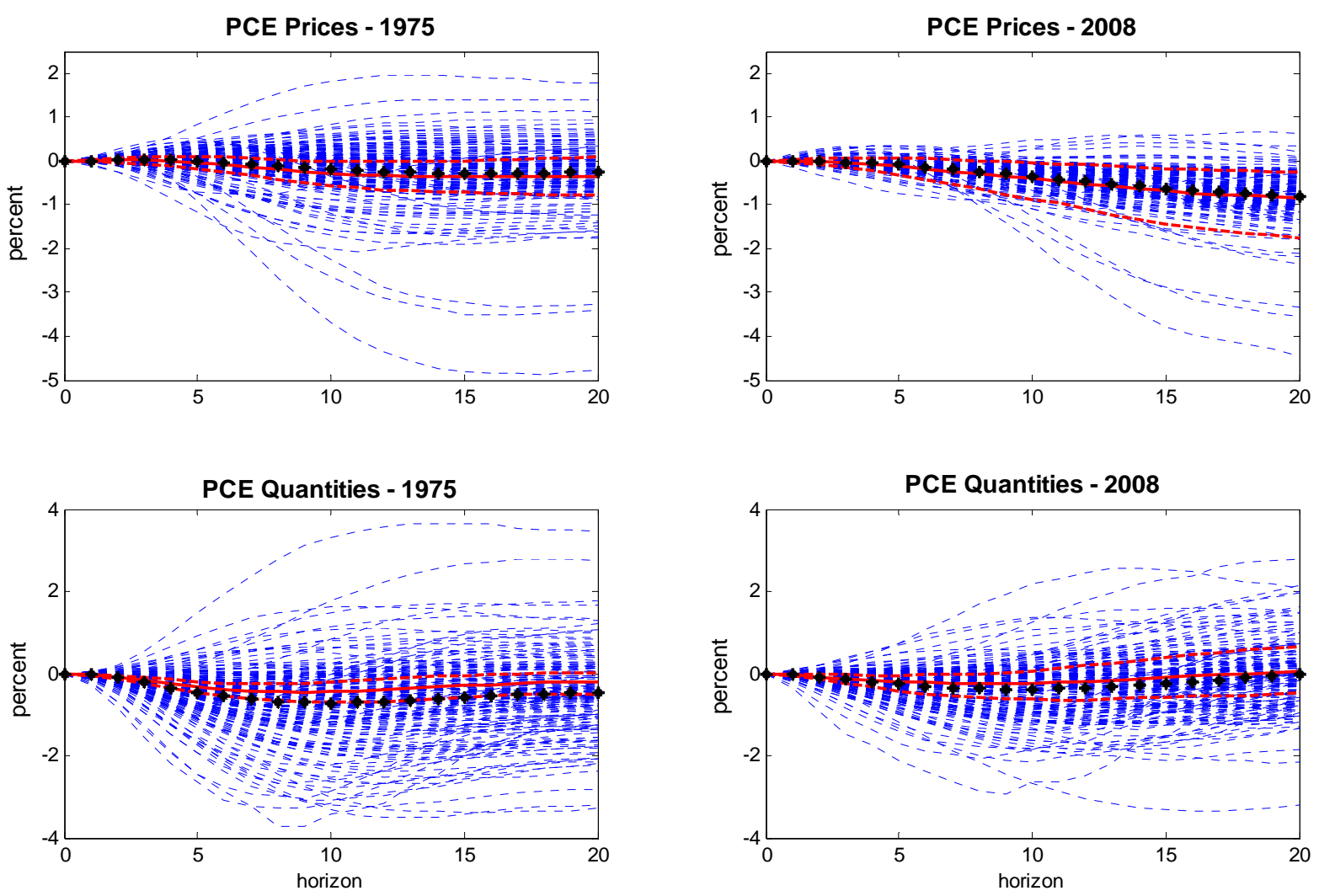

PANEL B
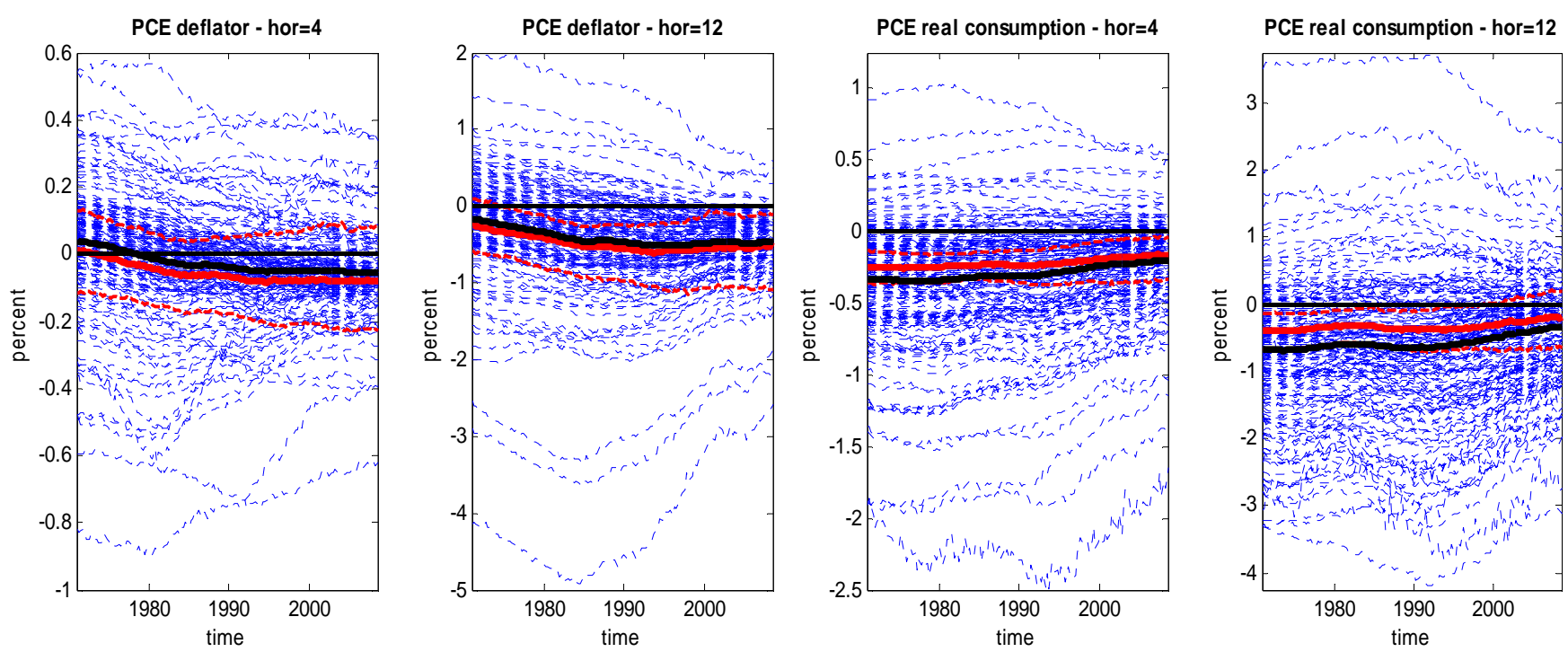

Figure 2: Median impulse responses to a $1 \%$ increase in the funds rate of disaggregated prices and quantities (dotted blue lines), aggregate PCE deflator and real consumption (solid red lines) with $16^{\text {th }}$ and $84^{\text {th }}$ percentiles (dashed red lines), unweighted average of individual responses (black stars).

Panel A: At two points in time - 1975Q1 and 2008Q1.

Panel B: At each point in time -4 and 12 quarters after the monetary policy shock. 

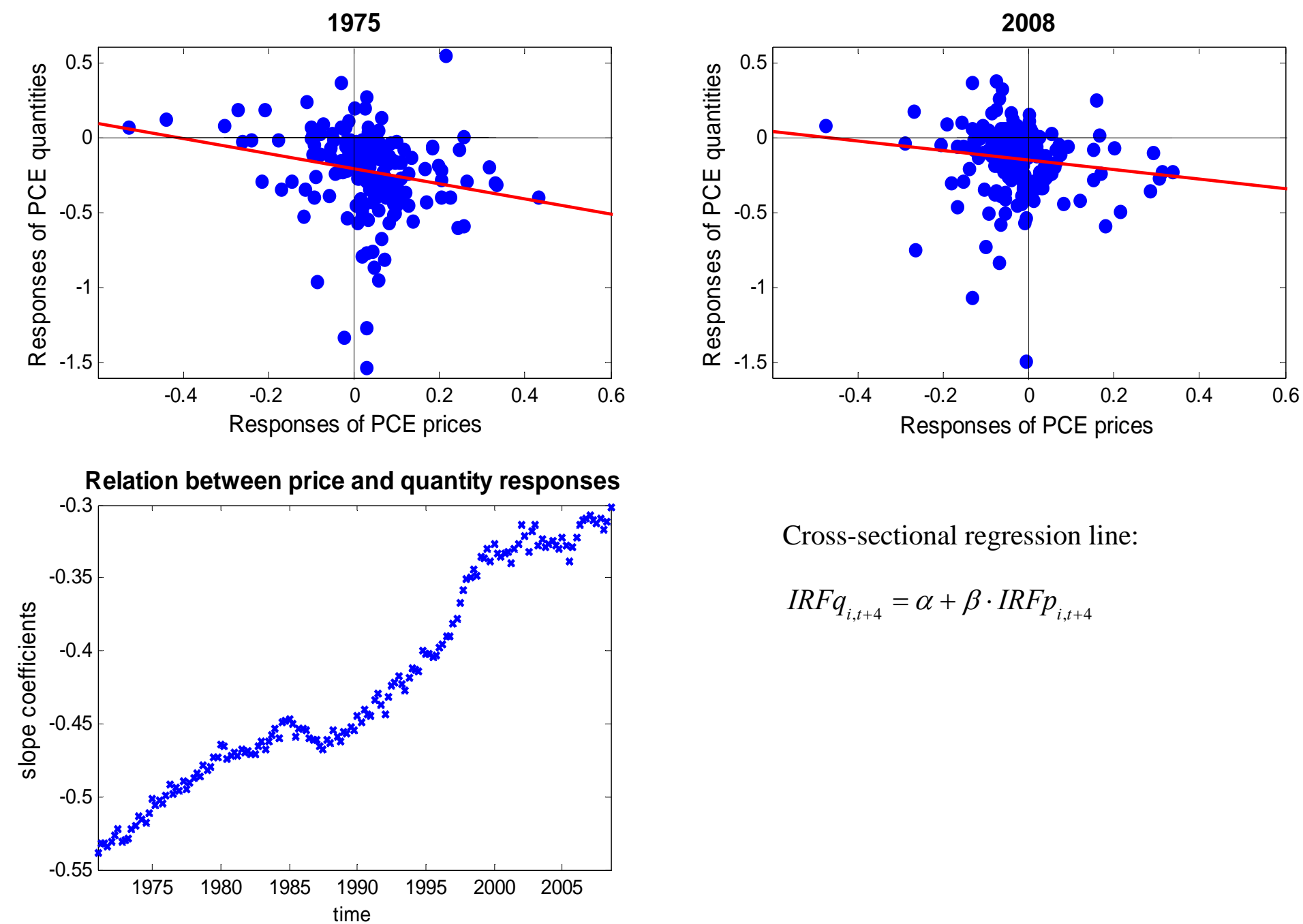

Cross-sectional regression line:

$$
I R F q_{i, t+4}=\alpha+\beta \cdot I R F p_{i, t+4}
$$

Figure 3: Relation between sectoral price and quantity responses after 4 quarters conditional on a monetary policy shock:

- scatter plot and cross-sectional regression line for 1975Q1 and 2008Q1.

- evolution of estimated slope coefficients $\beta$ over time. 
PANEL A
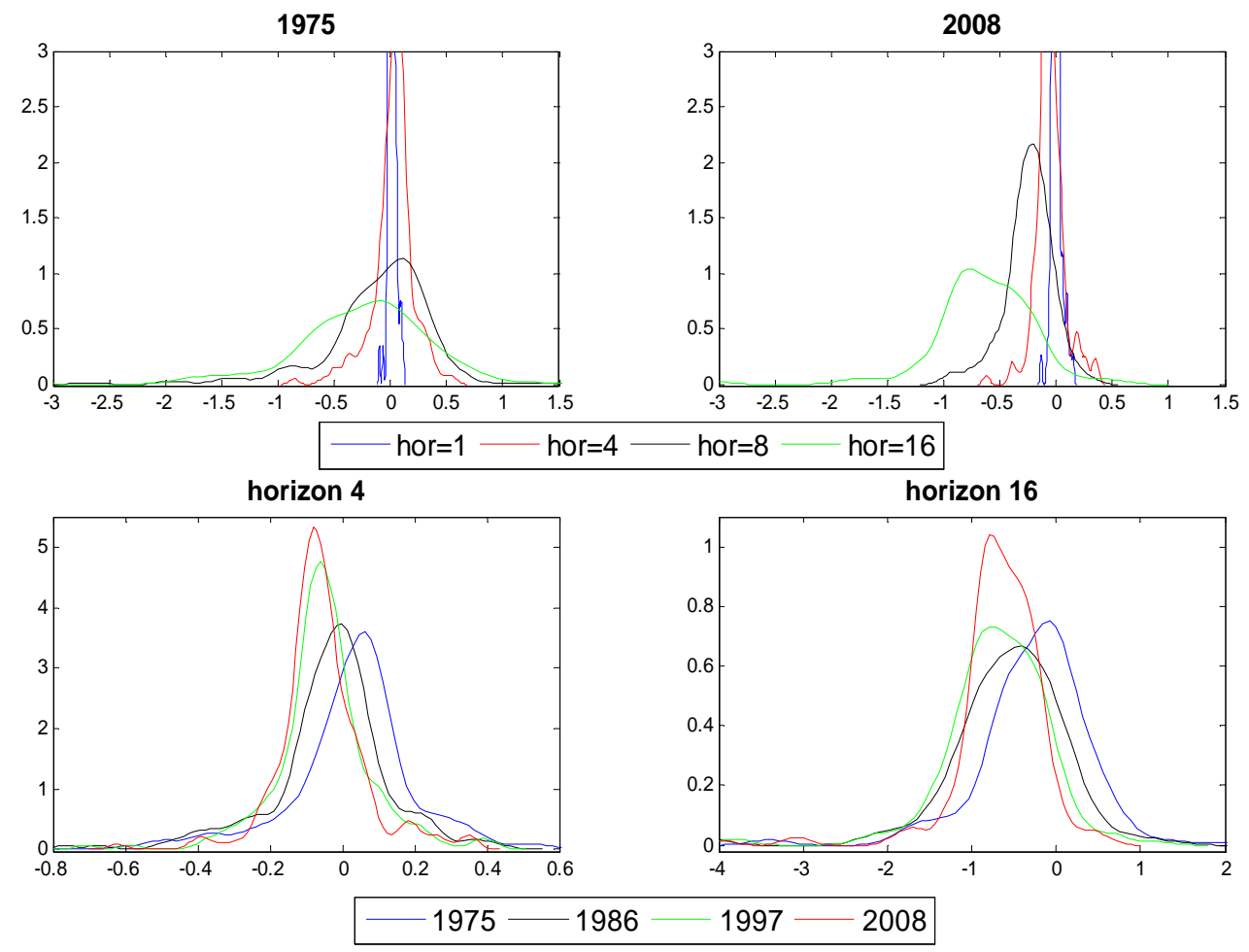

PANEL B
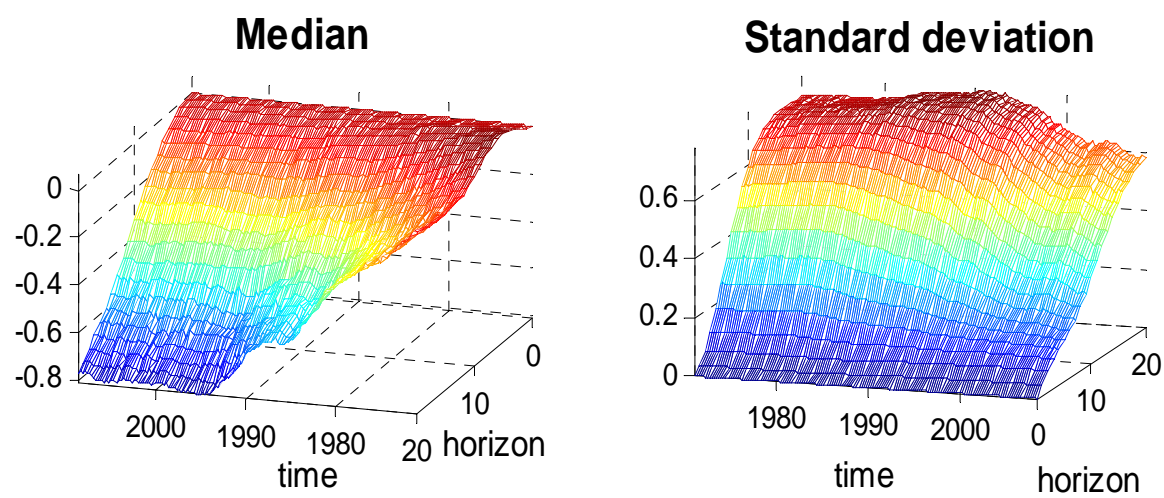

Figure 4: Panel A: Smoothed densities of cross-sectional price responses to a $1 \%$ increase in the funds rate at selected horizons and different points in time.

Panel B: Moments of the cross-sectional distribution of individual price responses over time. 
PANEL A
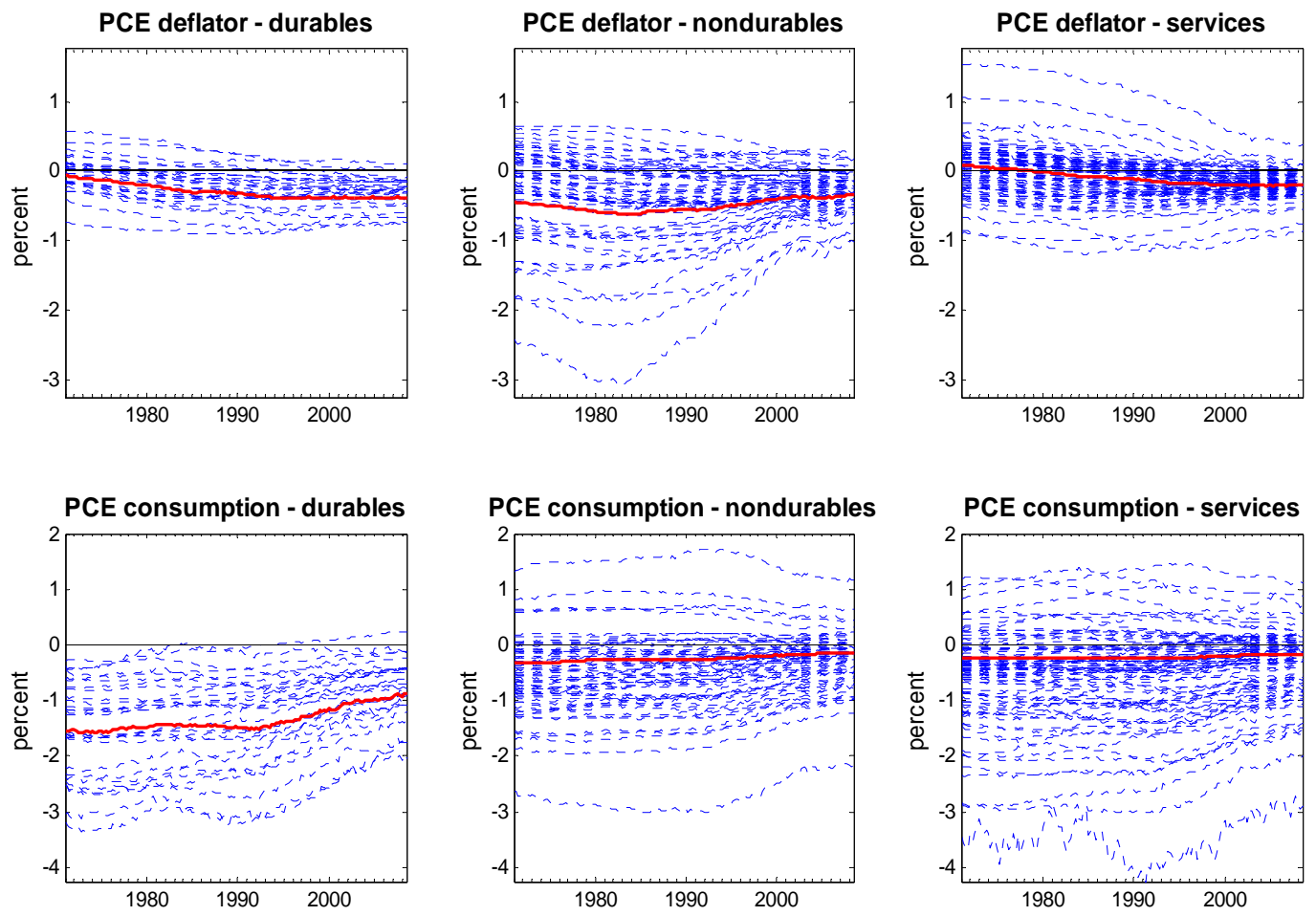

PANEL B
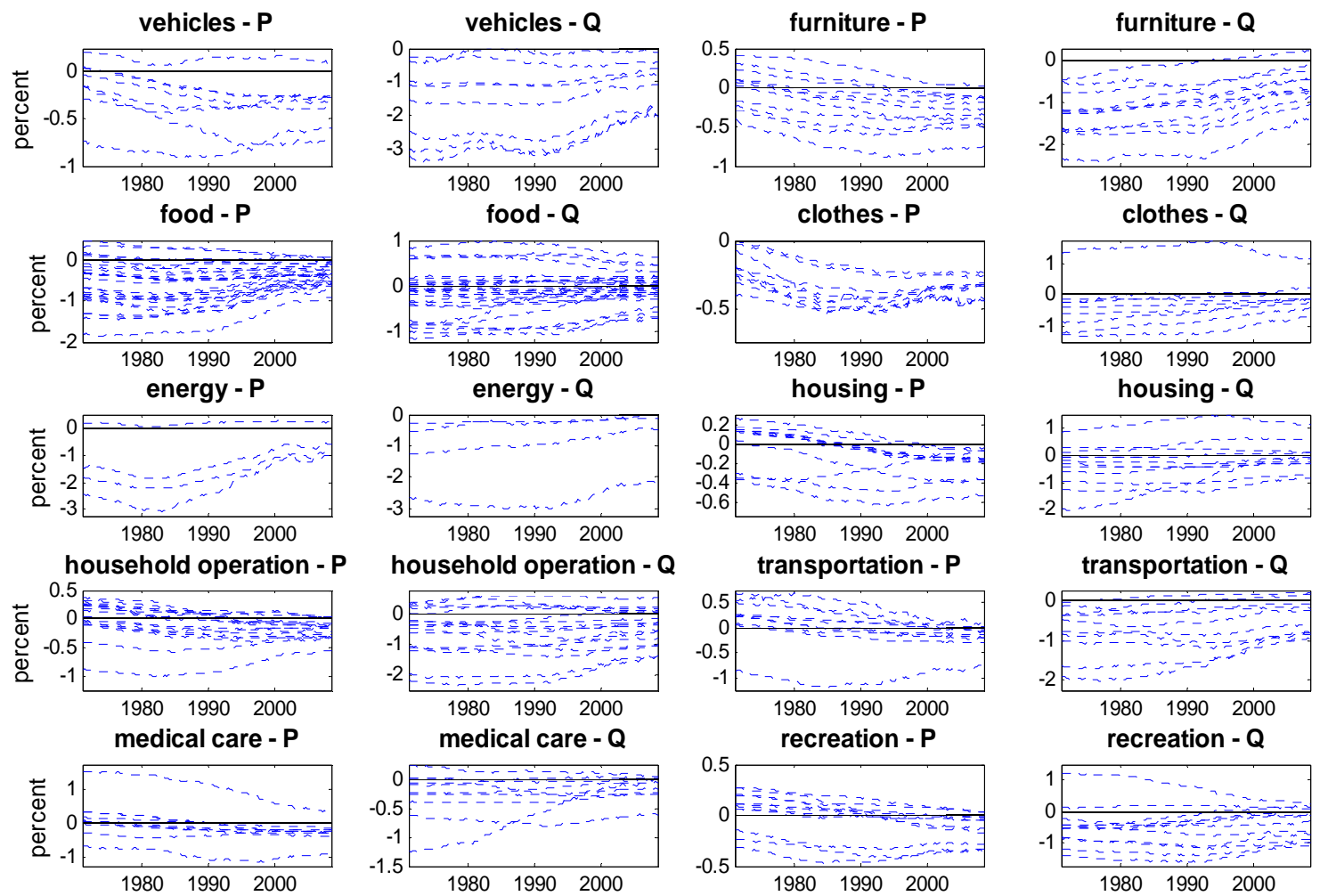

Figure 5: Time-varying median responses of prices and quantities 8 quarters after the shock (dotted blue lines). Panel A: Major PCE components along with response of aggregate sub-category (solid red lines). Panel B: Grouped according to different product categories. 

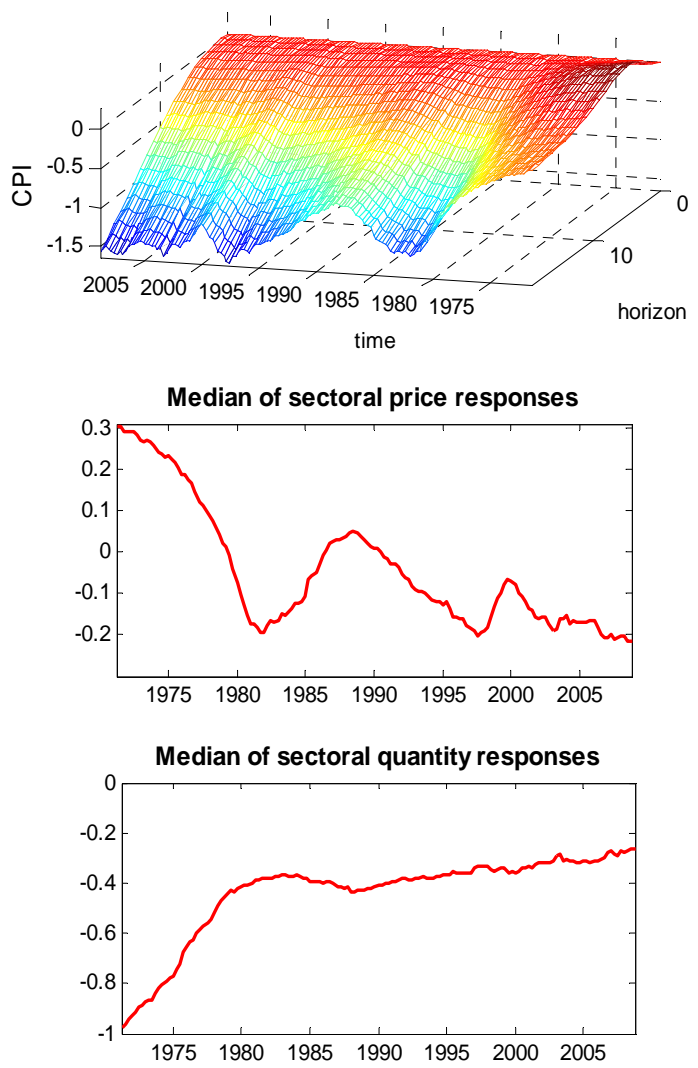

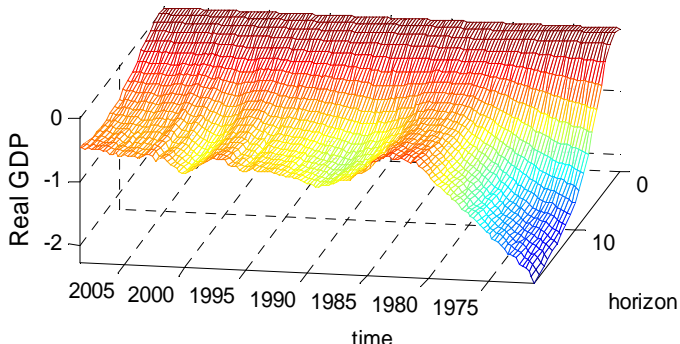

Standard deviation of sectoral price responses

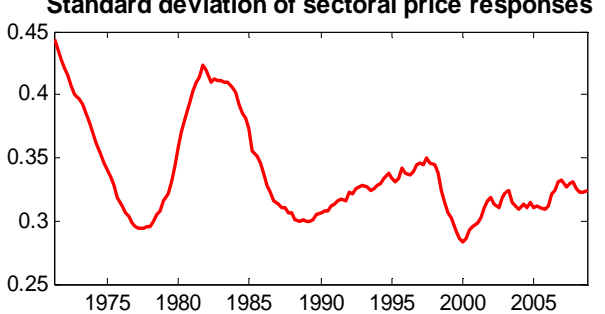

Standard deviation of sectoral quantity responses

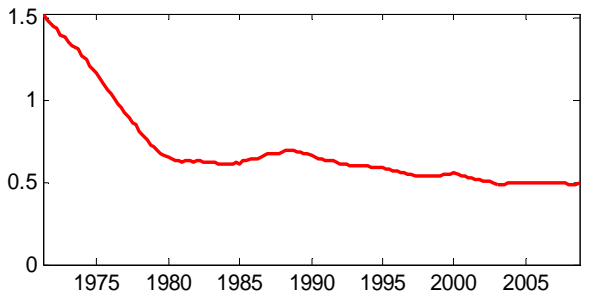

Figure 6: Time-varying median impulse response functions for CPI and real GDP at each point in time (first row) and median and standard deviation of sectoral price and quantity responses at the two-year horizon (second and third row) derived from the extended model. 
Price responses (flex firms)

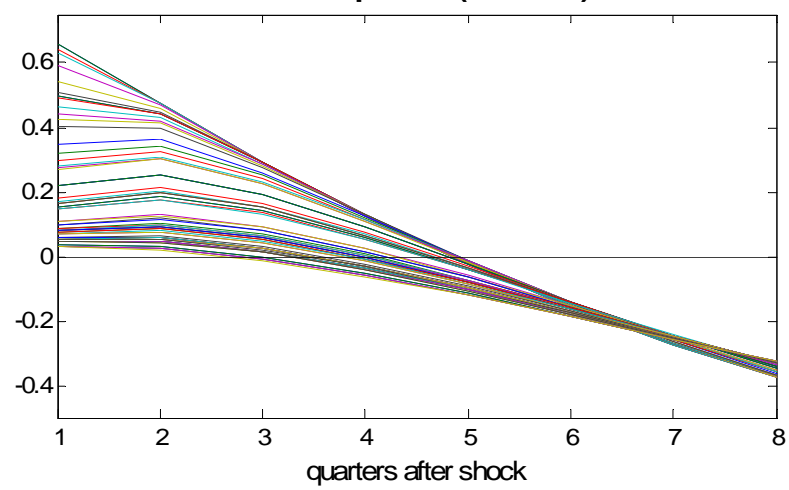

Price responses (inflex firms)

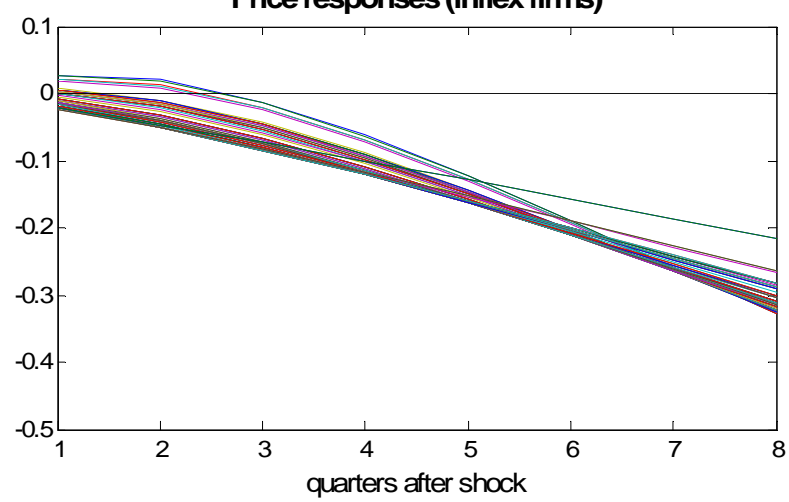

Aggregate price response
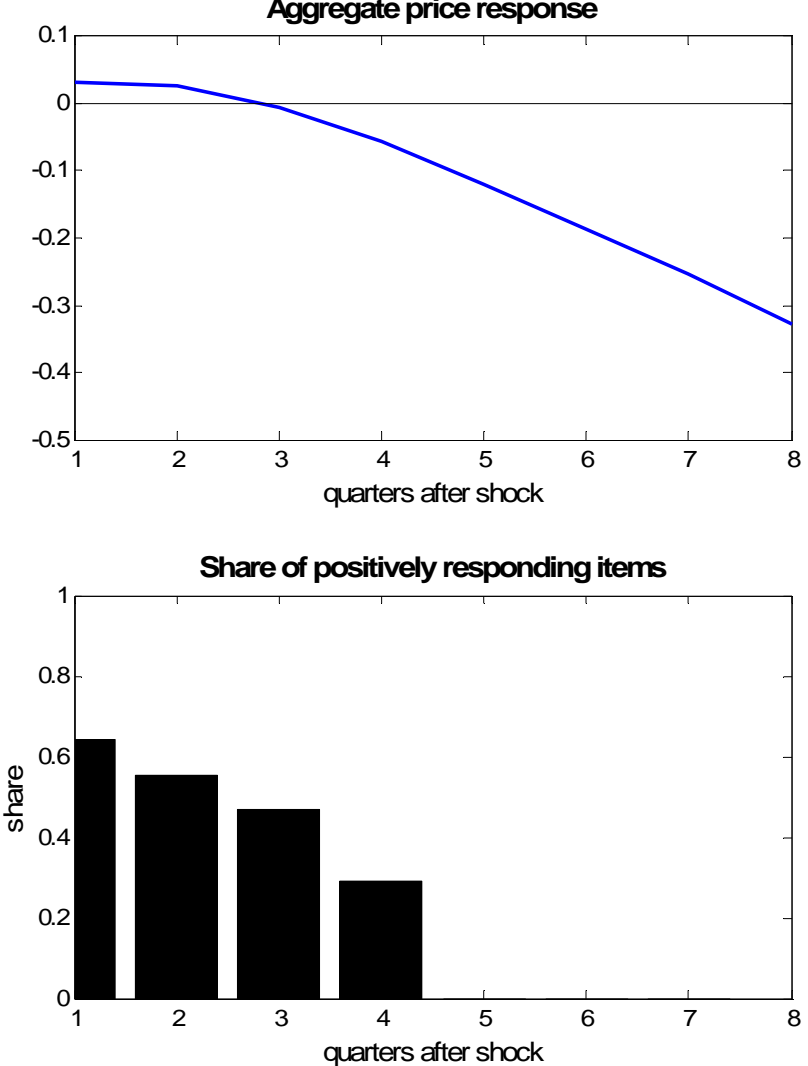

Figure 7: Sectoral and aggregate impulse responses from a multi-sector sticky-price model after a contractionary monetary policy shock. 
Panel A
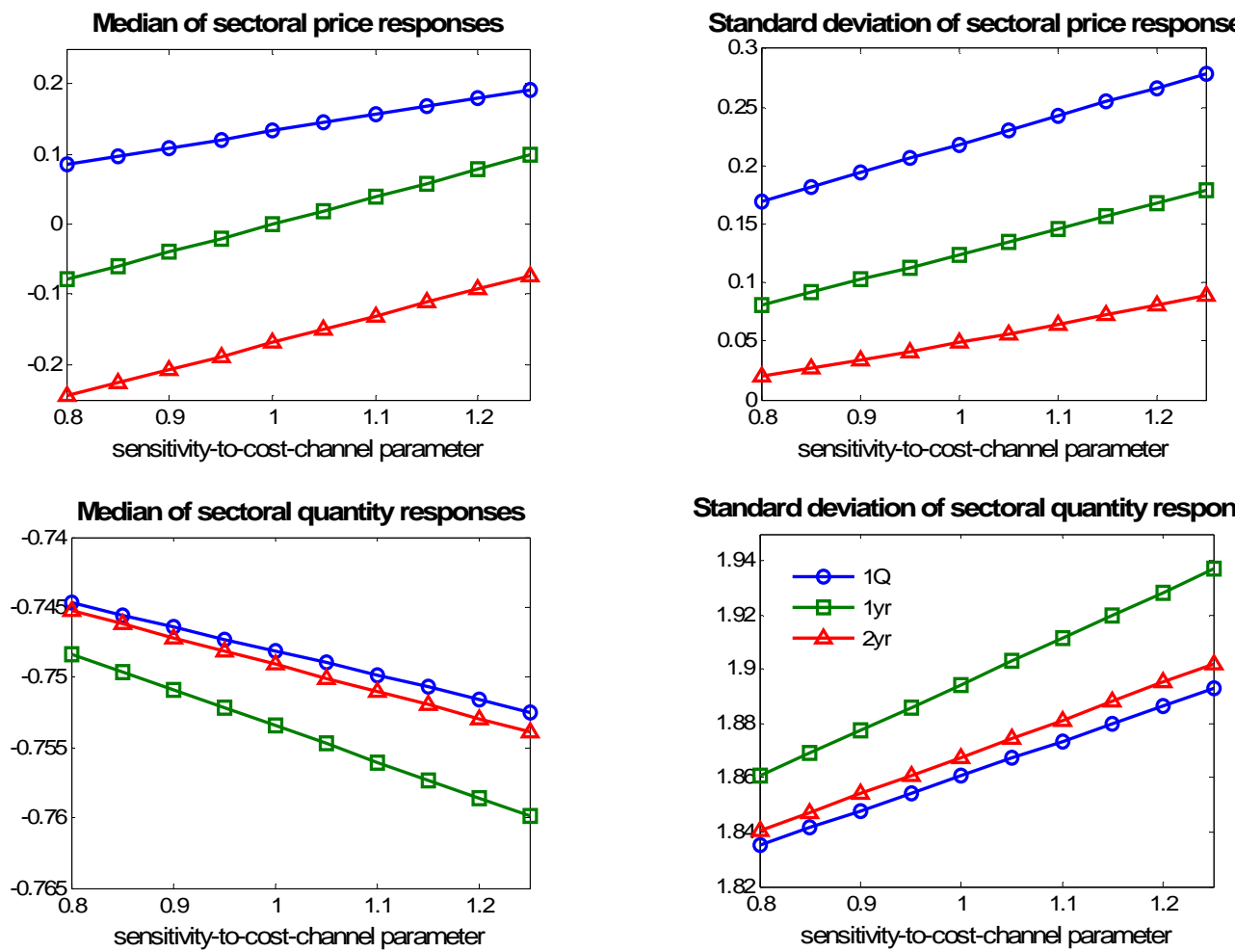

Standard deviation of sectoral quantity responses

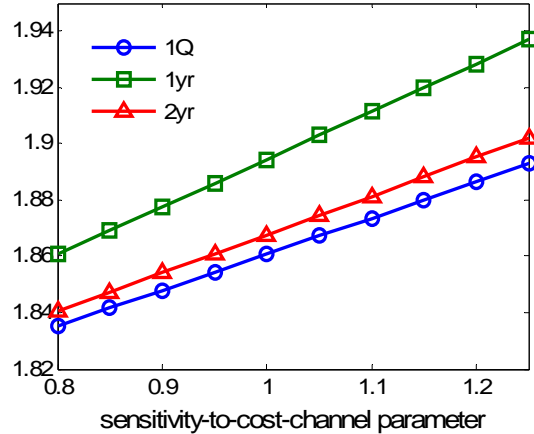

Panel B
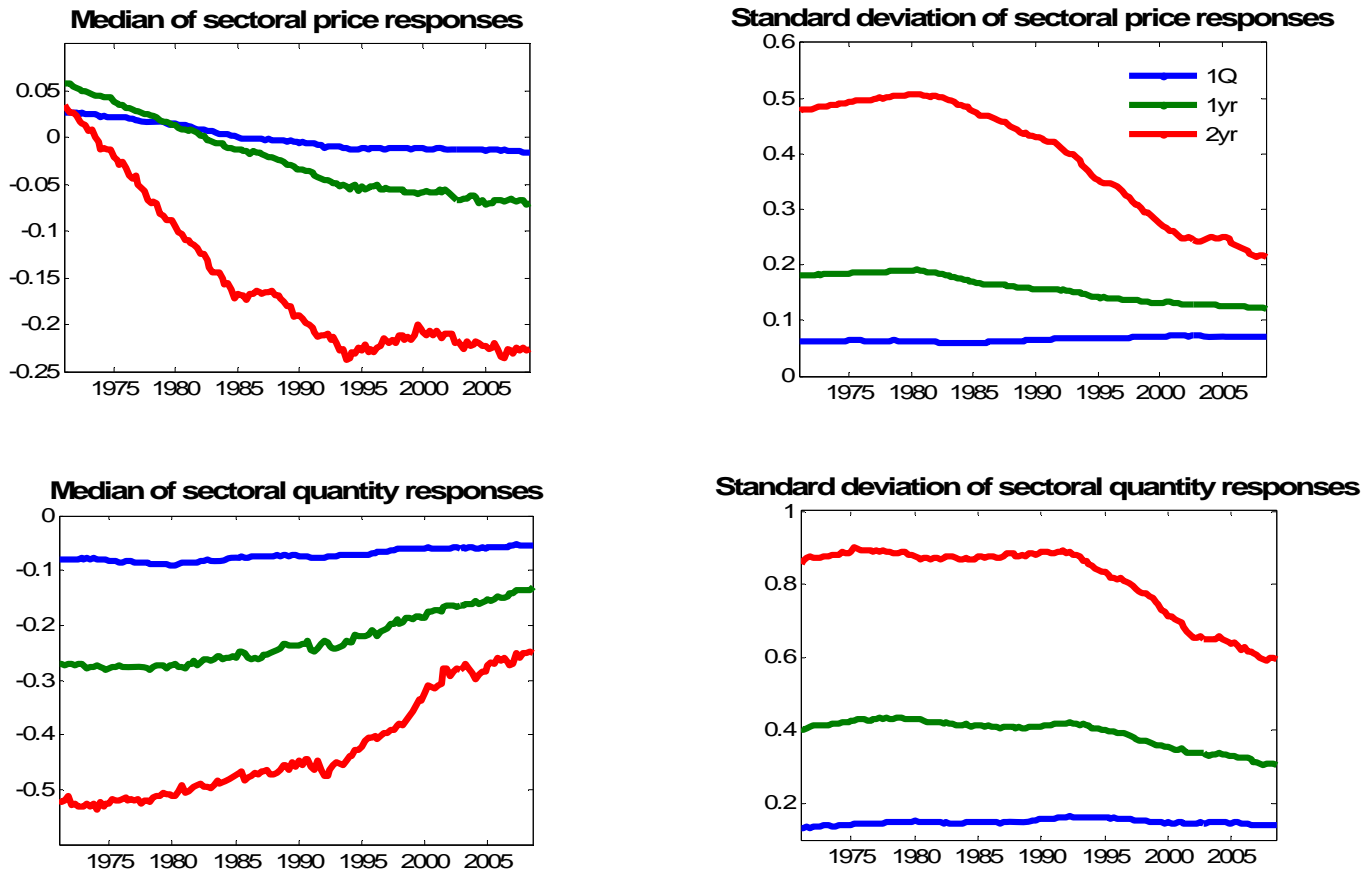

Figure 8: Model-based and empirical moments of cross-sectional price and quantity distributions one quarter (blue line), one year (green line) and two years (red line) after monetary policy shock. Panel A: Evolution of median and standard deviation of sectoral price and quantity responses for a range of parameter values that measure firms' sensitivity to the cost channel.

Panel B: Evolution of median and standard deviation of sectoral price and quantity responses over time. 


\section{Panel C}
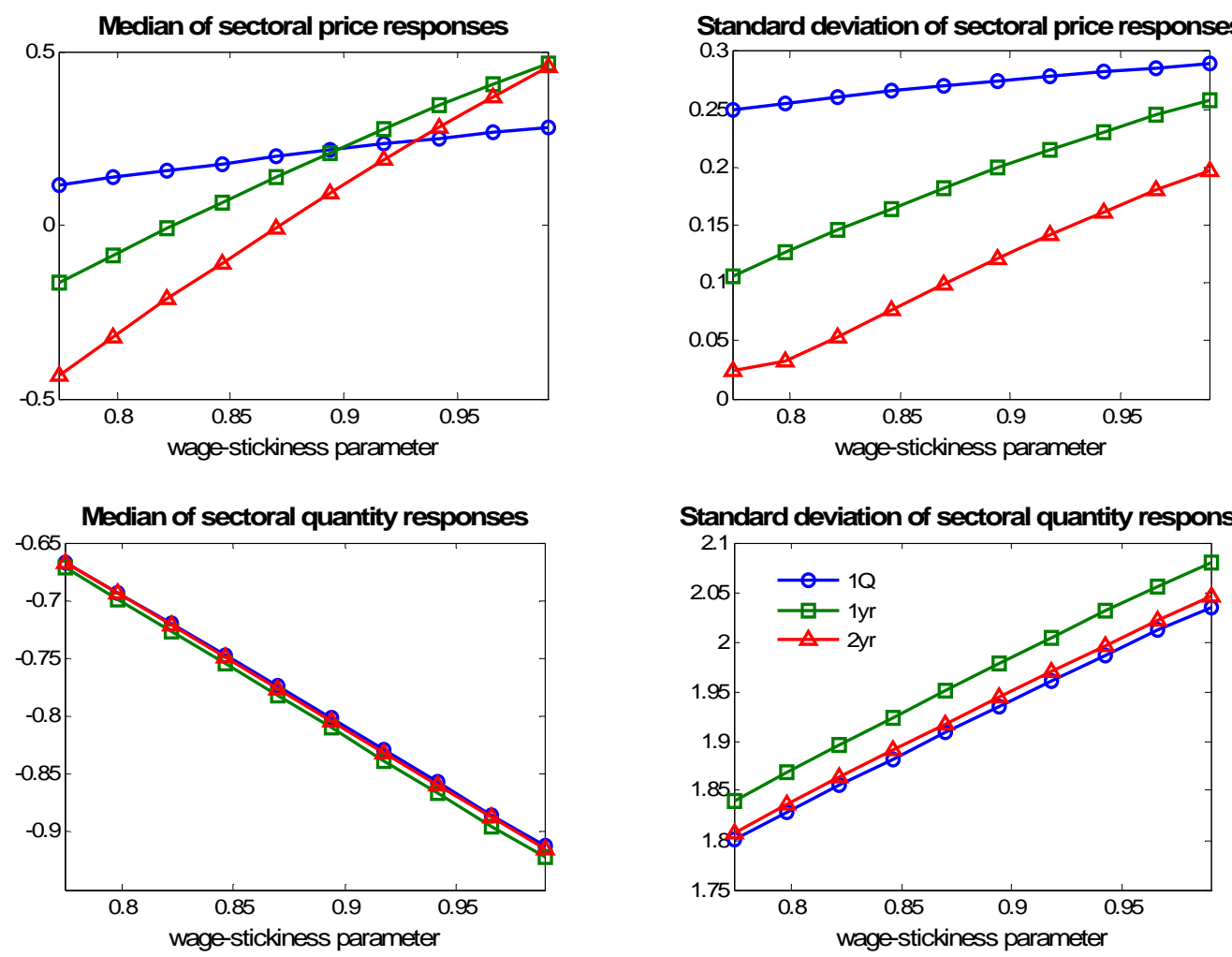

Figure 8 (continued):

Panel C: Evolution of median and standard deviation of sectoral price and quantity responses for a range of parameter values that measure the degree of wage flexibility. 